\title{
عرض تقرير: حالة الأمن الغذائي والتغذية في العالم 2021*
}

أ.د. سحر البهائي

مقدمة

قبــلـ تفشي جائحسـة كوفيـــ-19 لما يكن العالم في المسار الصحيح نحو القضـاء على الجوع وســوء التغذية بجميــع أشـــالها بحلول عام 2030، وفي ظل تفشي الجائحة أصبح الأمر يشكل صعوبة بالغة نحو تحقيق هذا الهدف في الوقت المحدد، لما سببته الجائحة من انكماش لم يسبق له مثيل منذ الحرب العالمية الثانية، وتدهور لأوضاع الأمن الغذائي و التغذية لملايين الأشخاص حول العالم بمن فيهم الأطفال. و ولا تز ال الجائحة تكثف عن وجود مواطن ضعف في النظم الغذائية، الأمر الذي يهدد حياة السكان وسبل معيشتهم في جميع أنحاء العالم، و لا سيما السكان الأشدّ ضعفًا وأولئك الذين يعيشون في أوضاع معيشية اجتماعية و اقتصادية هشة. يُعد تقرير حالة الأمن الغذائي و التغذية في العالم، و الذي جاء هذا العام تحت عنوان تحويل النظم الغذائية من أجل تحقيق الأمن الغذائي وتحسين التغذية وتوفير أنماط غذائية صحية ميسورة الكلفة للجميع، التقيبم العالمي الأول لانعدام الأمن الغذائي وسوء التغذية في عام 2020، ويقدم التقرير بعض الدلائل على ما سيكون عليه حال الجوع وسوء التغذية بحلول عام 2030 في ظلّ سيناريو أكثر تعقيداً بسبب الآثار المستمرة لجائحة كوفيد-19. وتشلّط هذه الدلائل الضوء على الحاجة إلى التمعن في كيفية معالجة حالة الأمن الغذائي والتغذية في العالم على نحو أفضل. ويتضدن التقريز ثلاثة فصول رئيسية، بالإضافة لرسائل التقرير وفصلي المقدمة و الخلاصة، و الملاحق.

يبدأ التقرير بعرض ووصف لآخر المعلومات و المستجدات والاتجاهات في مجالي الأمن الغذائي و التغذية، ويستعرض ثوقعاته لبعض مؤشرات حالة الجوع بحلول عام 2030 في سيناريو يزداد تعقبذا جراء استمر ار تداعيات جائحة كوفيد-19، ويقدم التقرير تحليل للدوافع و العوامل الرئيسية التي تعيق تحقيق الأمن الغذائي و التغذية في العالم. ثم يناقش كيفية الانتقال إلى حلول للنظم الغذائية المتكاملة من أجل تحقيق الأمن الغذائي، و التغذية المحسّة، و أنماط غذائية صحيّة ميسورة التكلفة للجميع.

*ثارك في إعداد التقرير كلّ من منظمة الأغذية والزر اعة، والصندوق الدولي للتتمية الزراعية، ومنظمة الأمم المتحدة للطفولة

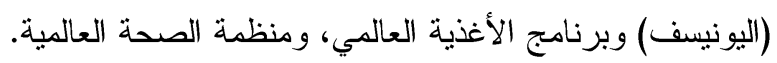
منظمة الأمم المتحدة للأغنية و الزر اعة و آخرون (2021). حالة الأمن الغذائي و التغذية في العالم: تحويل النظم الغذائية من أجل تحقيق الأمن الغذائي وتحسين التغذية وتوفير أنماط غذائية صحية ميسورة الكلفة للجميع. روما: منظمة الأغذية و الزر اعة.

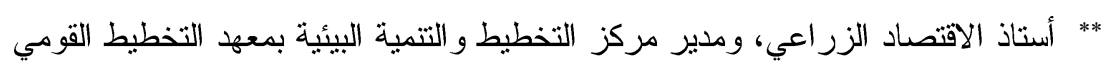


نعرض فيما يلي لأهم الرسائل التي خلص إليها التقرير، ثم نعرض للمحاور الرئيسية والقضايا التي

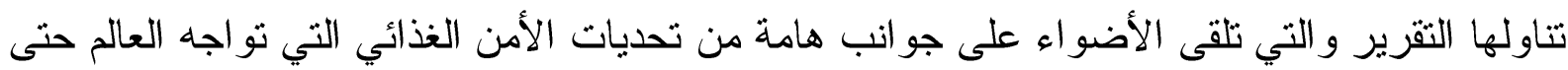

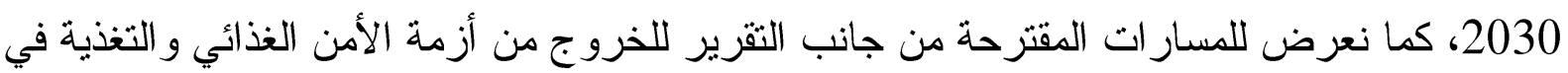
العالم، ونختم بمقترحات الثقرير لتحويل النظم الغذائية في العالم. أو لاً: الرسائل الرئيسية للتقرير 1. تؤكد التوقعات الجديدة أنه لن يتم القضاء على الجوع بحلول عام 2030 ما لم تتخذ إجراءات جدية

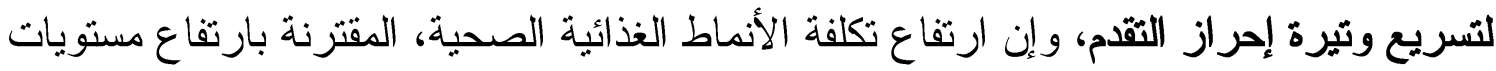
انعدام المساواة في الدخل، جعلت الأنماط الغذائية الصحية بعيدة المنال بالنسبة إلى حوالى الئي 3 مليار ات شخص عبر العالم، لا سيما الفقراء منهم. 2. يساهم الانتقال إلى أنماط غذائية صحية مستدامة في خفض نكاليف الصحة وتغير المناخ بحلول عام 2030، على اعتبار أن التكاليف المستترة لهذه الأنماط الغذائية أدنى من نكاليف أنماطئ أنماط

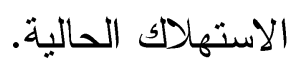

3. ساهمت كل من النزاعات المسلحة، والتقلبات المناخية، وانخفاض الإنتاجية، وعدم كفاءة سلاسل

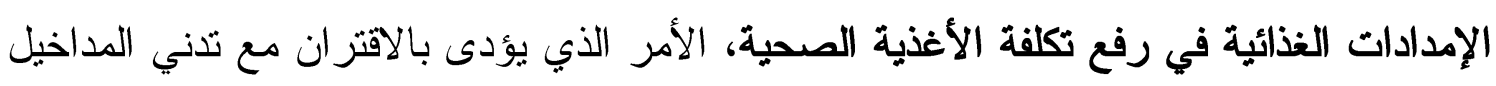
إلى عدم القدرة على تحمّل تكلفة أنماط غذائية صحية.

4. أهمية تحويل النظم الغذائية لتكون أكثر قدرة على الصمود في وجه معوقات وتحديات تحقيق الأمن

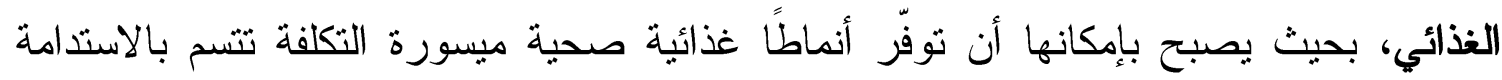

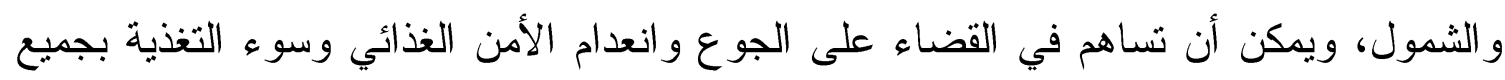

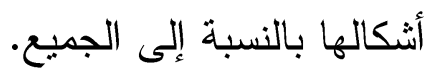

5. تأثيرات سلبية لجائحة كوفيد-19 على معدل انتشار أشكال متعددة من سوء التغذية، ويمكن أن

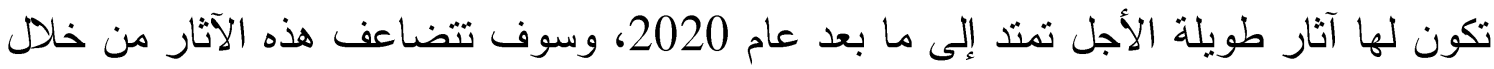
تأثثر ات انتقال سوء التغذية من جيل إلى آخر وما يتزتب عن ذلإ بلك من تداعيات بالنسبة إلى الإنتاجية. 6. هناك ستة مسارات يمكن اتباعها لتحويل النظم الغذائية، وهى : تحقيق التكامل بين السياسات

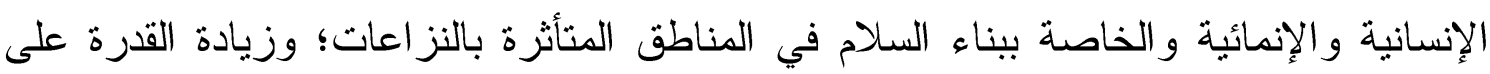

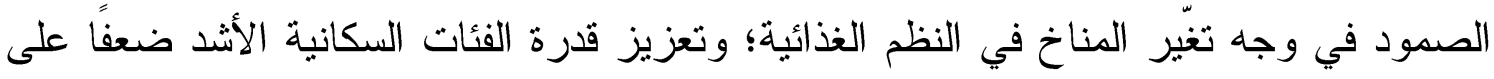

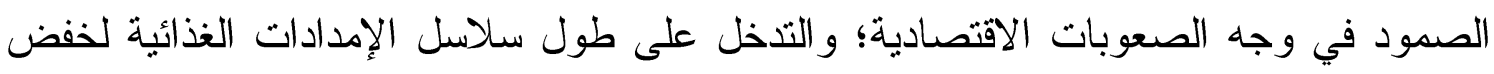

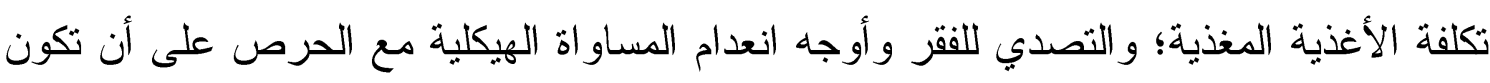
التخخلات شاملة ومر اعية لدصالح الفقر اء؛ وتعزيز البيئات الغذائية وتغيير سلوك المستهلكين من

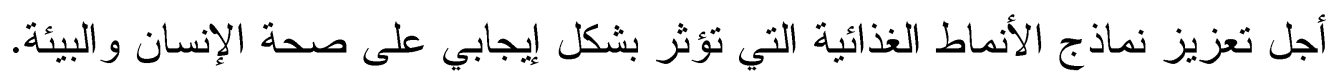


7. أهمية ضمان الاتساق في صياغة السياسات والتشريعات وتتفيذها على مستوى النظم الغذائية والصحية والبيئية والخاصة بالحماية الاجتماعية، للتوصل إلى حلول أكثر كفاءة وفعالية للنظم الغذائية من أجل توفير أنماط غذائية صحية ميسورة الكلفة بشكل مستدام وشامل.

ثانياً: محاور وقضايا رئيسية للتقرير 1. مؤشرات الأمن الغذائي والتغذية

يشير التقرير إلى تزايد مستوى الجوع في العالم عام 2020 في ظلّ تفشي جائحة كوفيد-19، حيث

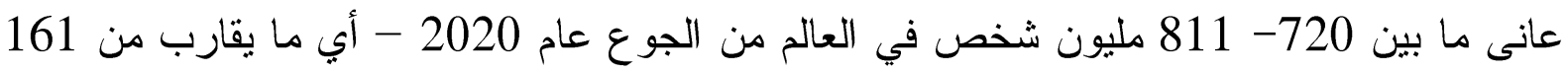

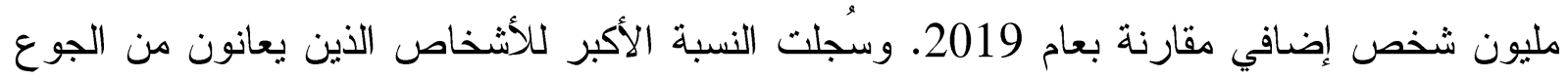
بقارة أفريقيا حو الى 21\% من سكانها، مقابل 9\% في آسيا، 9.1 \% و في أمريكا اللاتينية و البحر الكاريبي.

علاوة على ذلك، عانى حو الي 9.9\% من سكان العالم عام 2020 من نقص التخذية أي ما يقارب من

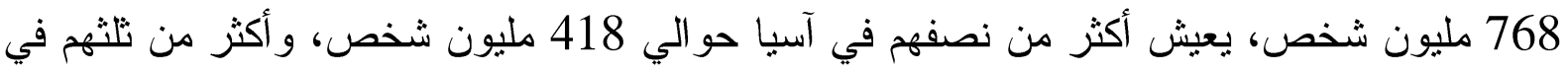
أفريقيا حو الي 282 مليون شخص وحوالي 59.7 مليون شخص في أمريكا اللاتينية و البحر الكاريبي.

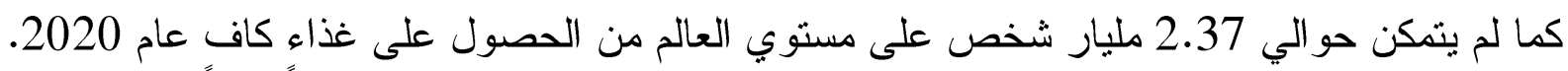
و عانى حو الي 12\% من سكان العالم من انعدام الأمن الغذائي الثديد.

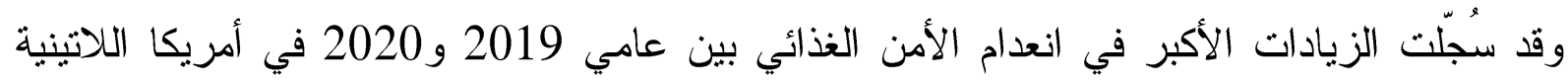

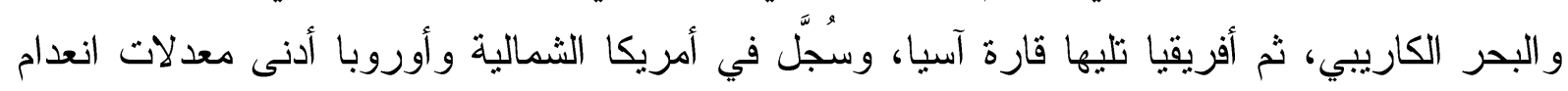

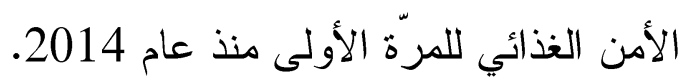

ويؤكد التقرير على أن مئات الملايين من الأشخاص يعانون بالفعل من الجوع وسوء التغذية قبل تفشي

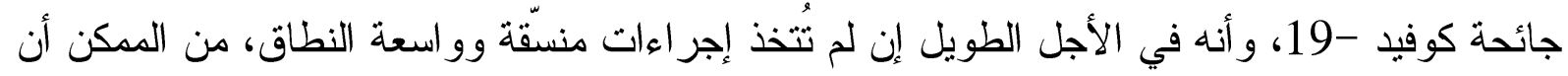
تؤدي الآثار المتمعة للإصابة بكوفيد -19 وتدابير التخفيف ذات الصلة و الانكماش العالمي الناجم عنها إلى حدوث اختلالات في سير عمل النظم الغذائية يترتب عليه عو اقب وخيمة بئبة بالنسبة إلى الصحة و التغذية.

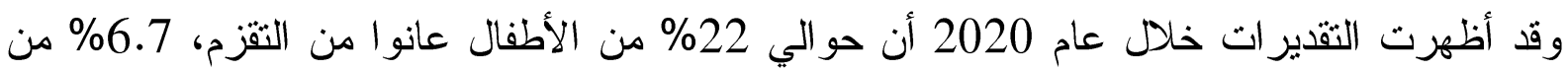

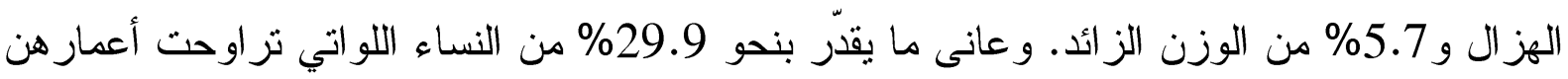

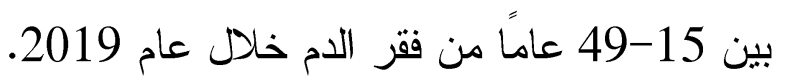
وسجّلت اتجاهات متز ايدة في معدل انتشار السمنة لدى البالغين في جميع الأقاليم. مما يؤكد أن التقام

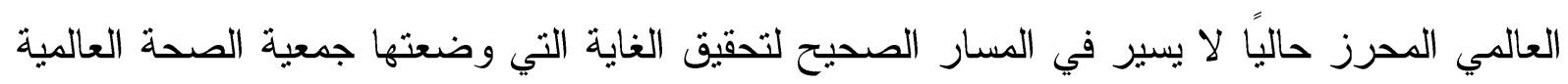
و التي تقضي بوقف هذا الارتفاع بحلول عام 2025. 
ويخلص الثقرير إلى أن بلدان عدة في مختلف أنحاء العالم تو اجه تحديات عديدة في سعيها نحو ضمان

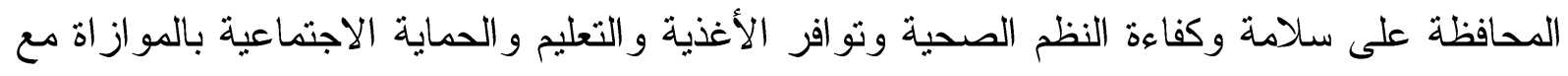
تصديها لجائحة كوفيد-19.

2.توقعات وسيناريوهات القضاء على الجوع وسوء التغذية بحلول عام 2030 تم تقدير توقعات معدل انتثار النقص التغذوي حتى عام 2030 باتباع نهج هيكلي يستتد إلى نموذج إنجاء

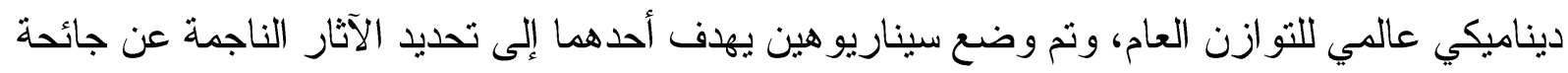

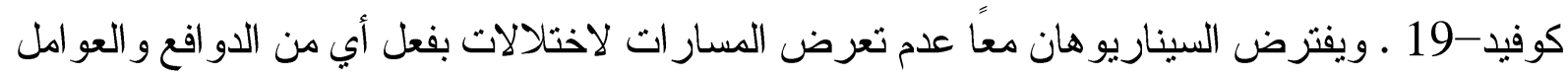

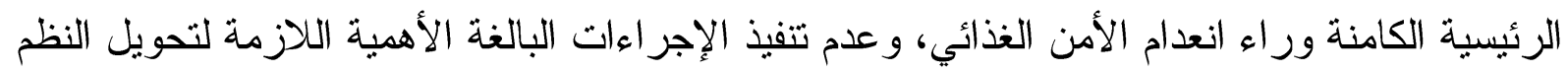

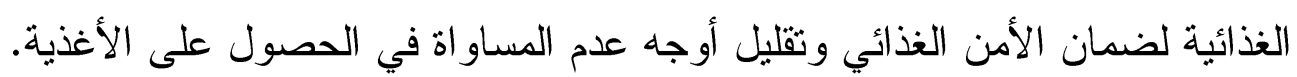

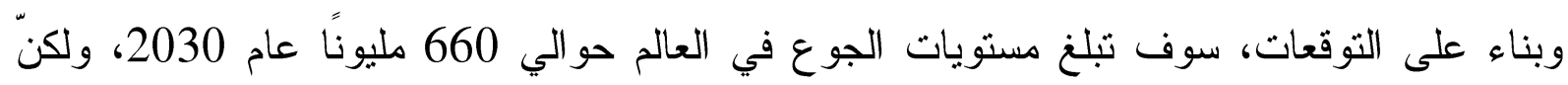

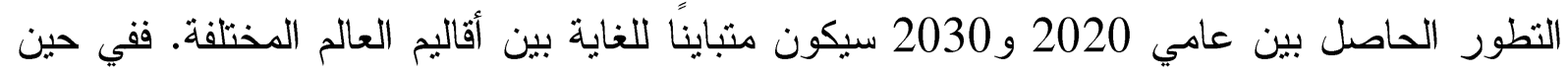
يتوقع حدوث انخفاض كبير في آسيا (من 418 مليونًا إلى 300 مليون شخص)، تشئل

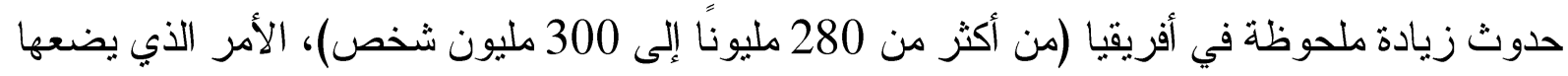

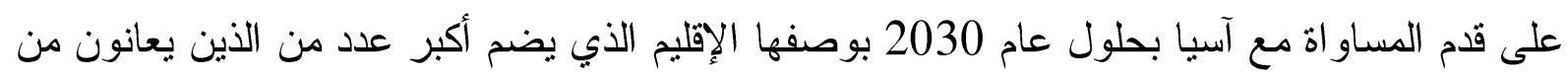
النقص التغذوي.

ويرى التقرير أنه من الصعب التتبؤ بمسار السنوات القادمة في ظلّ استمر ار انكثاف الآثار الاقتصادية

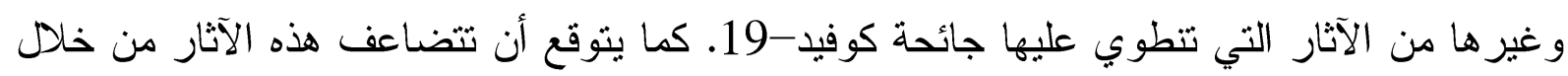

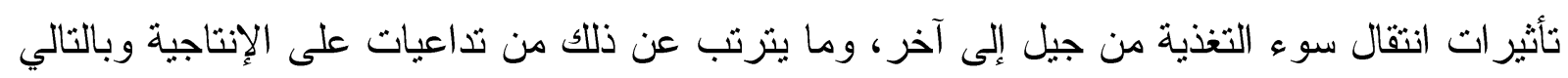
على الانتعاش الاقتصادي.

من ناحية أخرى، تحرز جميع الأقاليم الفرعية تقريبًا بعض الثقام لخفض التقزم لاى الأطفال، إلا أن

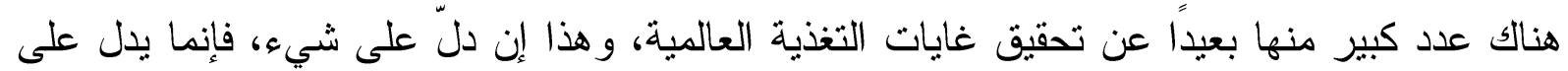

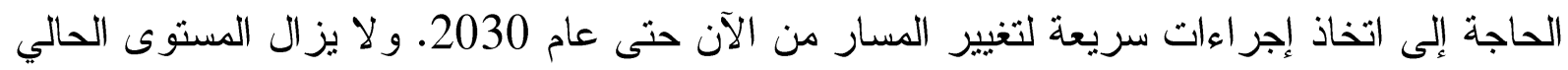
للهزال أعلى بكثير من الغاية العالمية لعام 2025 التي تبلغ 5\% و الغاية العالمية لعام 2030 التي تبلغ

كما تجدر الإثشارة إلى أن معظم الأقاليم لم تسجل أي تقدم يذكر في فيما يتعلّق بمعدل انتشار الوزن الزائد

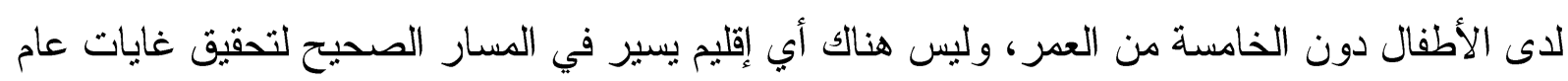

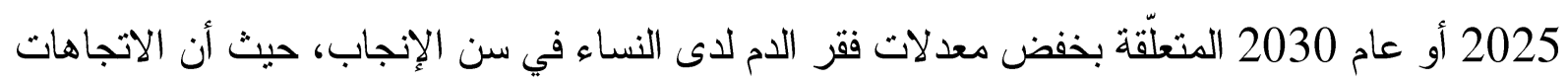

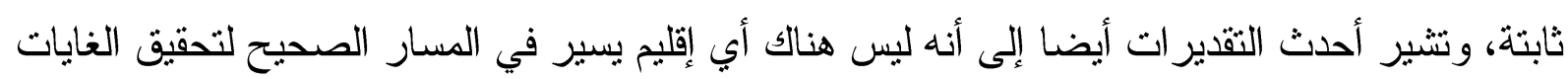

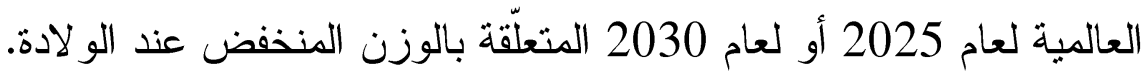


3.تأثيرات فادحة لجائحة كوفيد-19 على الأمن الغذائي والتغذية فى أقاليم العالم ساهمت جائحة كوفيد -19 في تدهور إمكانية حصول الأشخاص على الأغذية، وأن حالة الأمن الغذائي

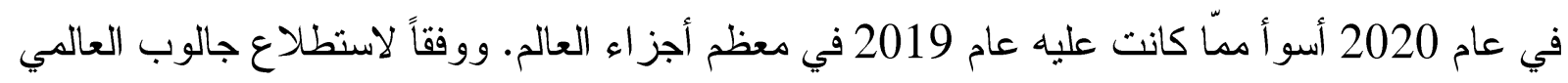

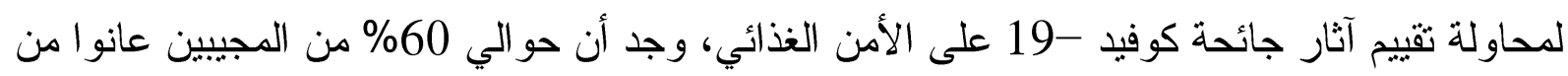

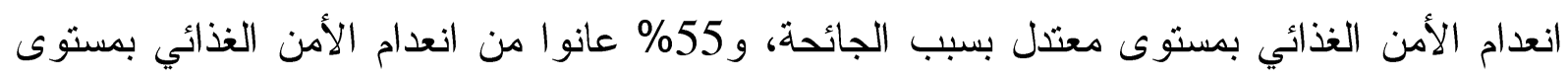
شديد لنفس السبب، أي أن الجائحة ساهمت في تراجع إمكانية حصول الأشخاص على على الأغذية.

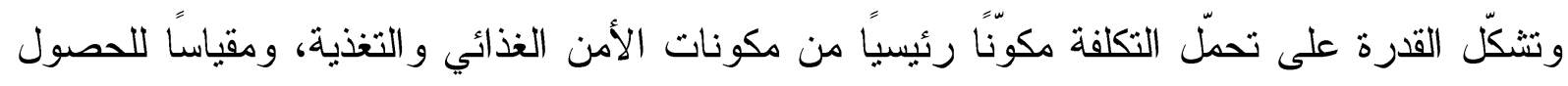

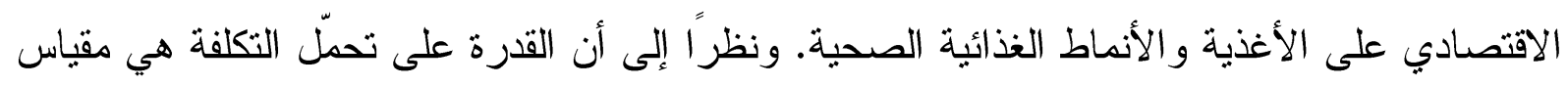

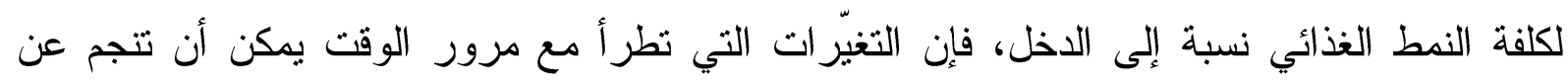

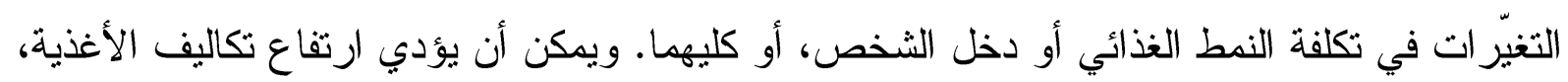

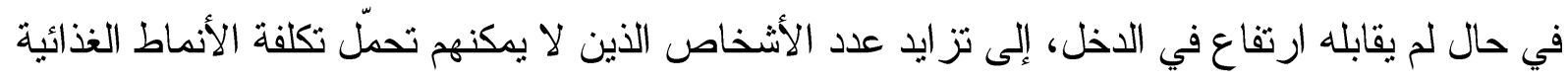
الصحية.

علاوة على ذلك، يمكن للمشاكل الأوسع نطاقًا التي تعصف بالاقتصاد، مثل حالات التباطؤ و الانكماش

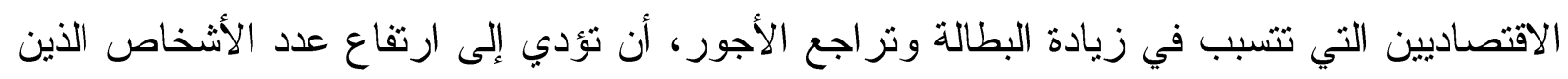

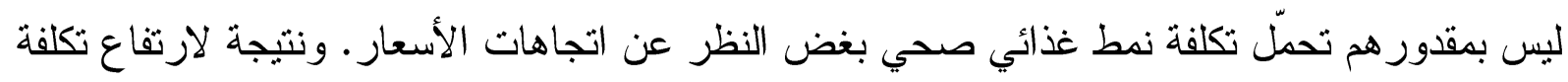

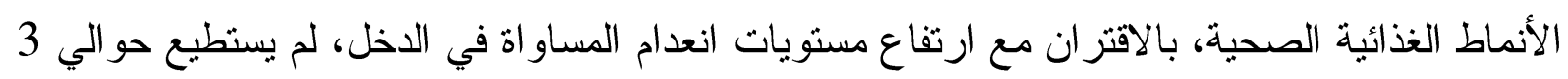

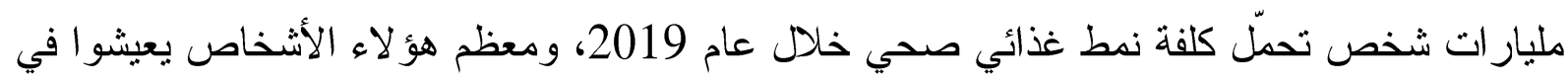

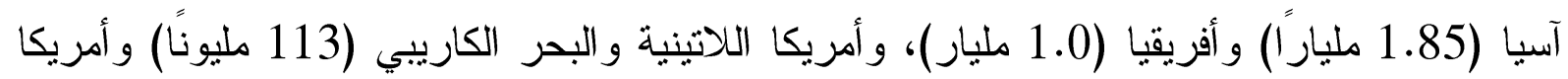
الشمالية وأوروبا (17.3 ملايين). كما أسفرت الظروف التي فرضنها جائحة كوفيد-19 مثل القيود المفروضة على الحركة، و إقفال أسواق

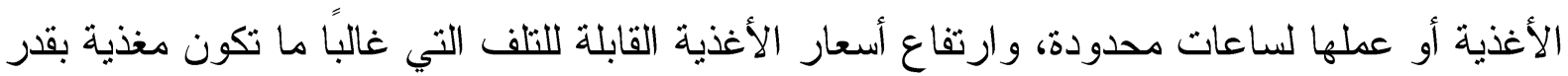

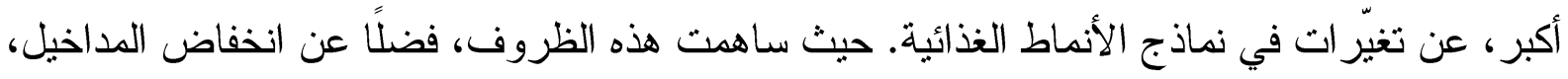

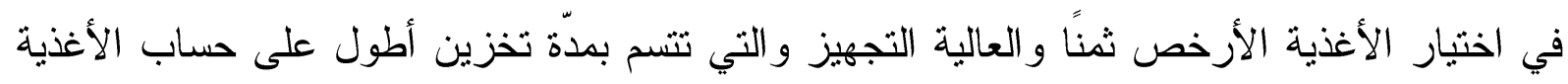

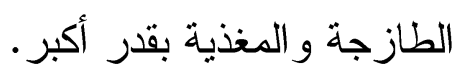

و أثّرت أيضًا جائحة كوفيد-19 على قدرة المجتمع الدولي على رصد النتائج التخذوية لدى الأطفال

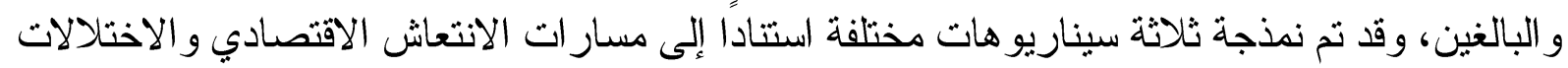

$$
\begin{aligned}
& \text { في الخدمات بسبب جائحة كوفيد-19 في عامي } 2021 \text { و 2022، ولثة وهي: ولئ } \\
& \text { أ. سيناريو الانتعاش السريع في عام } 2021 \text { (متفائل)، } \\
& \text { ب. سيناريو الموجة الثانية من العدوى في عام } 2021 \text { (معتدل)، }
\end{aligned}
$$




$$
\text { ت. سيناريو الاختلالات المستمرة والاتتعاش الذي يطول أمده (متشائم). }
$$

وتم استخدام نموذج عالمي للتوازن العام قابل للحوسبة ومرتبط ببيانات الدراسات الاستقصائية الأسرية

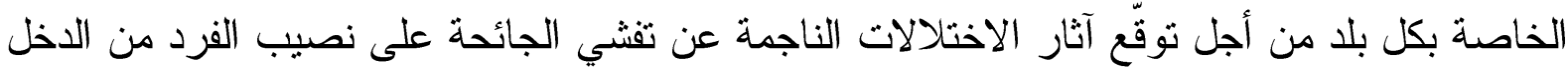

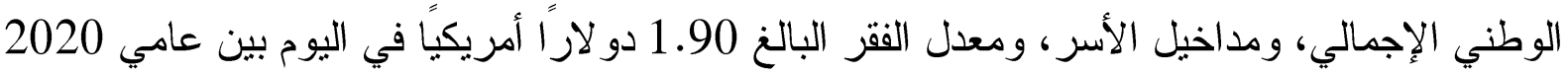

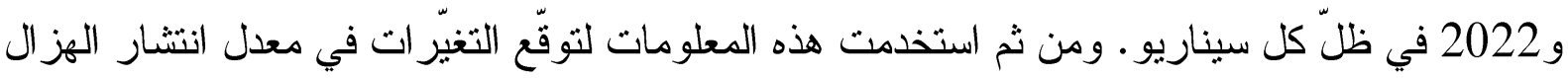
في كل بلد استتاداً إلى الرو ابط التاريخية الملاحظة. كما تم إدر اج التقدير ات الخاصة بالفقر و الهز ال و الافتر اضات المتعلّقة بمستوى اختلال الخدمات الصحية و التغذوية، وتم استتباط نتائج هذا النموذج المستخدم في 118 بلدًا من أجل ثقدير الآثار المحتملة في

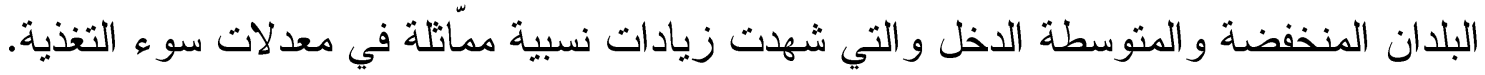

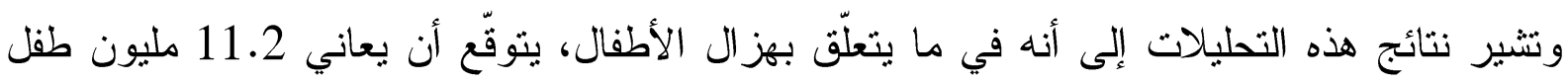

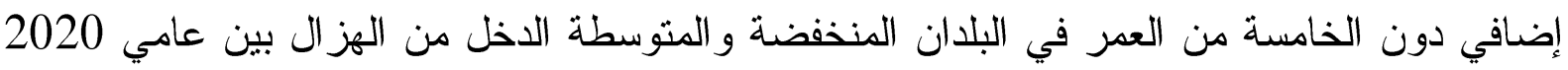

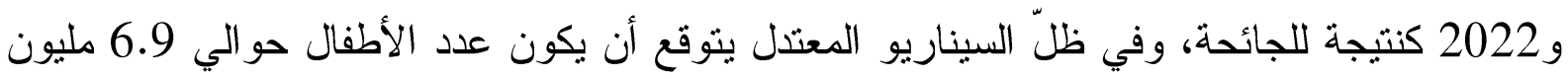

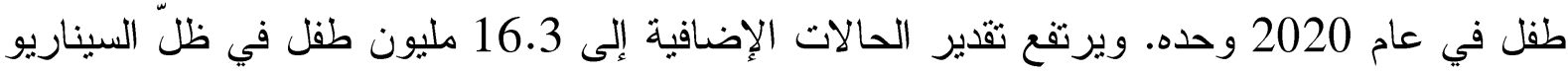

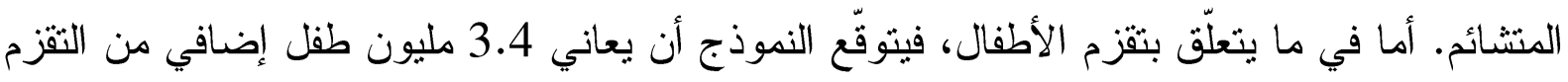

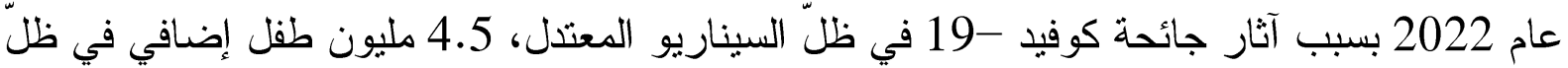
السيناريو المتشائم.

و استتادا إلى هذه السيناريو هات فـأنه من المتوقع أن يعاني ما يتراوح بين 6.1 -6.5\% من من الأطفال

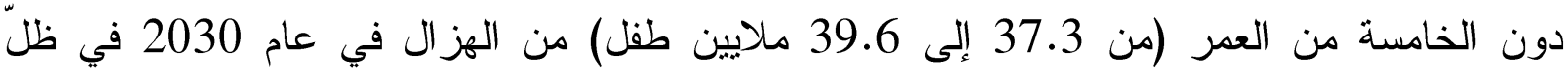

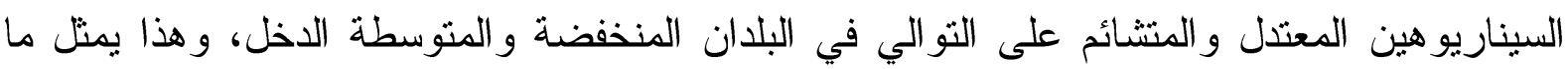
يترو اح بين 570 ألف و 2.8 مليون طفل إضافي مقارنة بالسيناريو الذي لم تتفشَ فيه الجائحة.

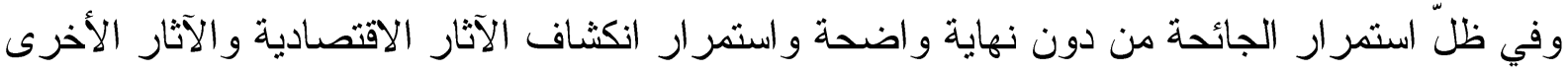

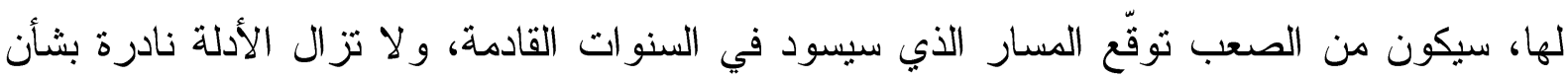
الآثار الفعلية لجائحة كوفيد-19 على مختلف أثكال سوء التخذية، بما في ذلك على معدل انتشار التقزم؛

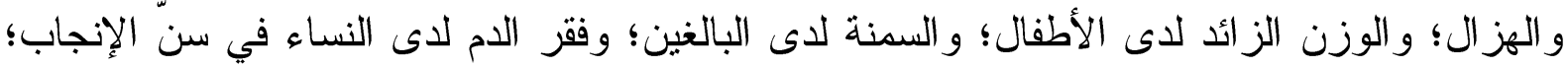

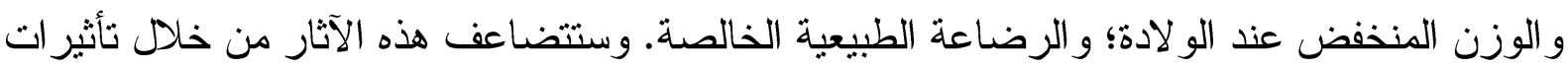

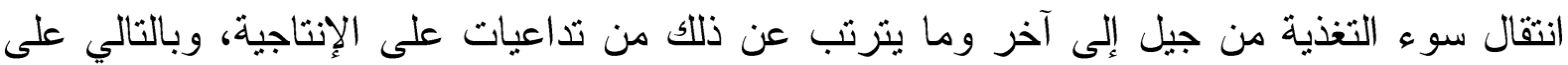

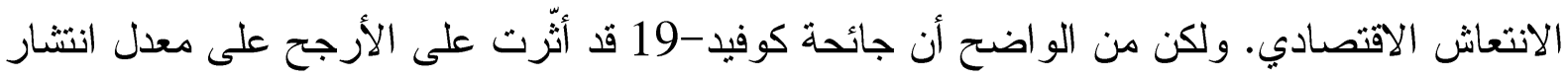

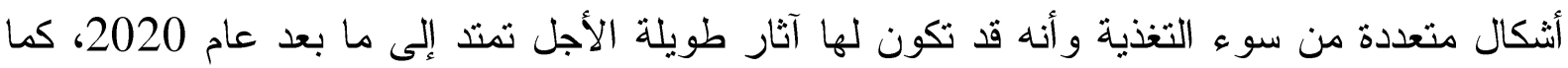

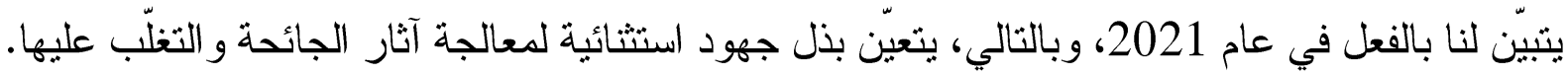


4.أسباب وعو امل إضافية كامنة وراء انعدام الأمن الغذائي وسوء التغذية في أقاليم العالم

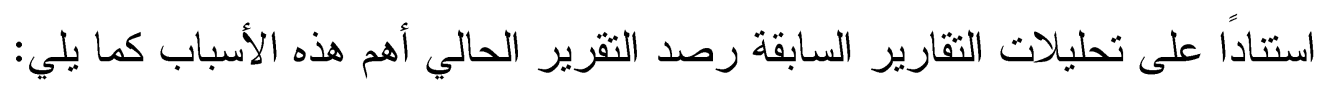

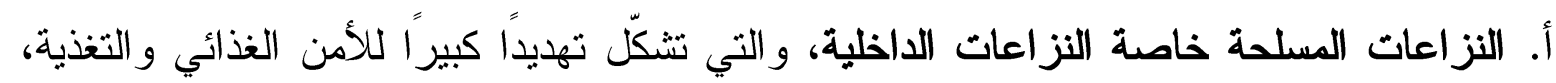
حيث يعيش حوالي 80\% من الأطفال الذين يعانون من التثزم في بلدان تثهد شكلًا من أثكال

$$
\text { النزاع أو العنف أو الهشاشة. }
$$

ب. التغيرات المناخية، والتي شكّت دافعًا رئيسيًا كامنًا وراء الارتفاعات الأخيرة في مستويات

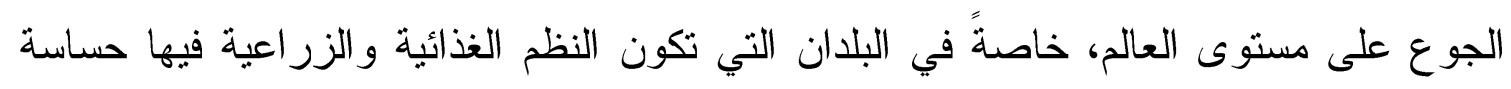

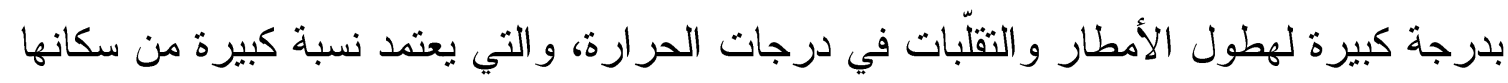

$$
\text { على الزر اعة لكسب سبل عيشها. }
$$

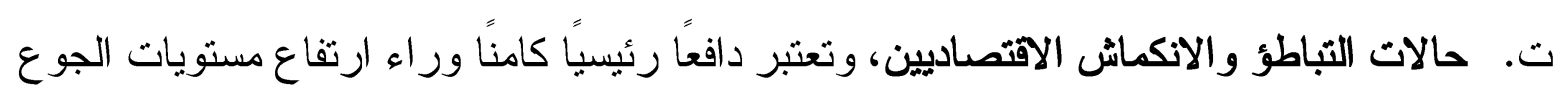

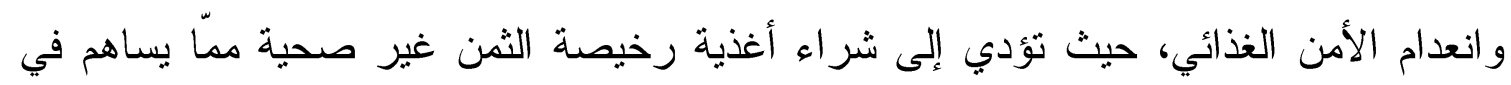
افتقار الأنماط الغذائية إلى الجودة التغذوية. ث.عدم القدرة على تحمّل تكلفة الأنماط الغذائية الصحية، ساهم في ارتفاع مستوى انعدام الأمن الغذائي وجميع أشكال سوء التغذية. ج. الفقر وانعدام المساواة، ويعتبران من القواسم المشتركة والعوامل التي تفاقم من الآثار السلبية لمأسباب الأخرى كافة.

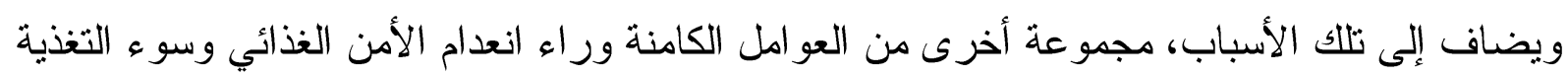

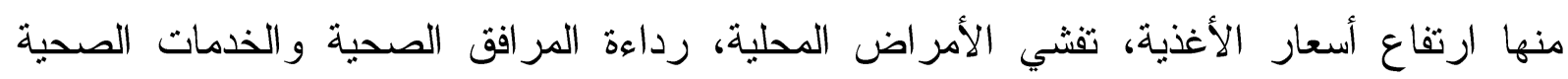

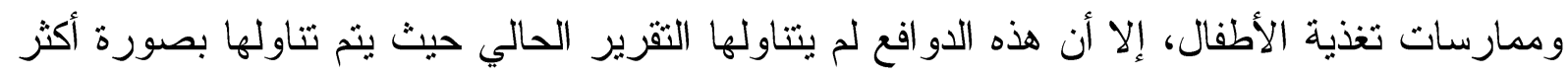
منهجية في تقارير عالمبة أخرى متعلقّة بالتغذية.

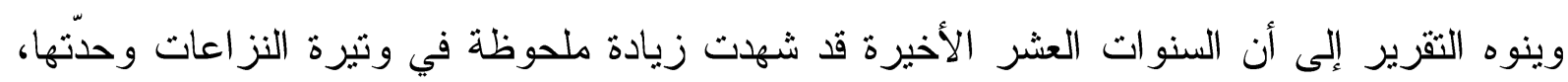

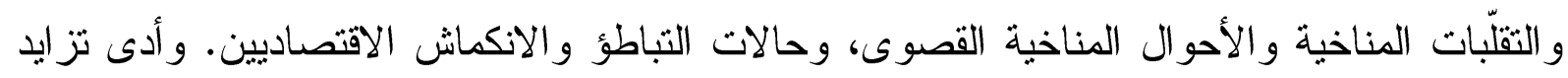

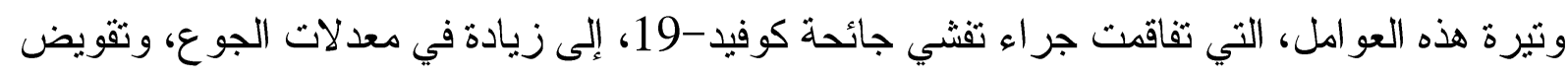

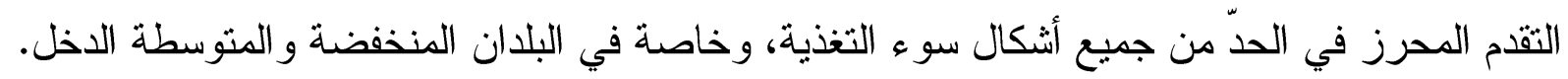

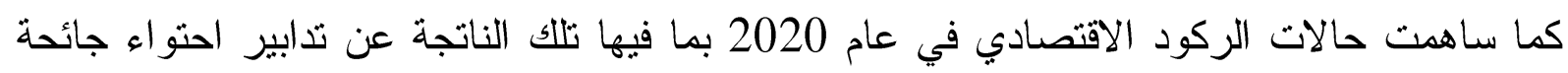

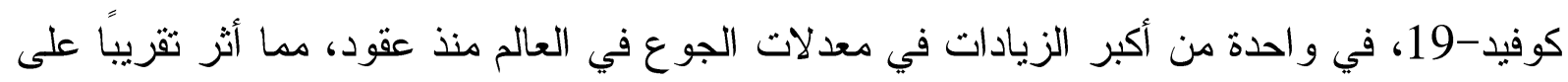

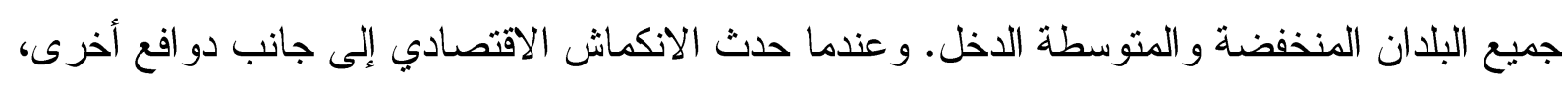

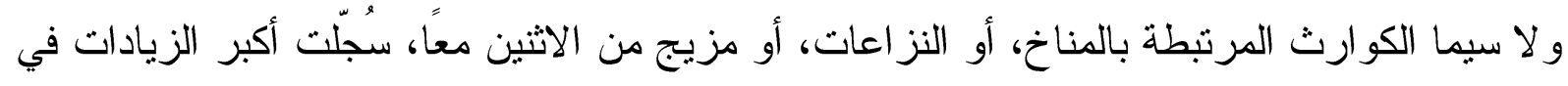
معدلات انتشار النقص التغذوي في أفريقيا، وتلتها آسيا. 
وبصفة عامة يتميز كل سبب من الأسباب السابق العرض لها بتفرّده وتداعياته، وعلى الرغم من كونها

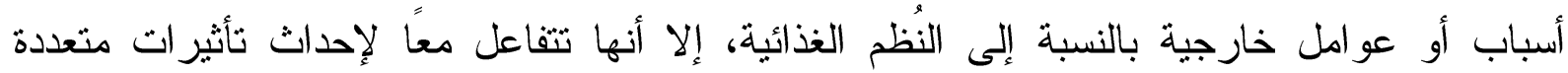
ومضاعفة في كثير من الجوانب داخل النظم الغذائية على حساب الأمن الغذائي و التغذية. وقد أوضح الثقرير أن حو الي 70\% من البلدان المنخفضة و المتوسطة الدخل تتأثر بسبب أو عامل و واحد

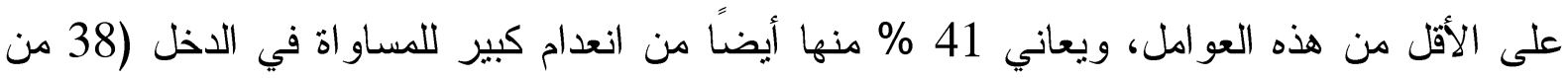
أصل 93 بلدًا)، الأمر الذي يفاقم أثر ها. الأبل كما ينوه التقرير إلى أن النظظم الغذائية تؤدى دورًا محوريًا ليس في تحديد كمية الأغذية المتاحة للاستهلالك

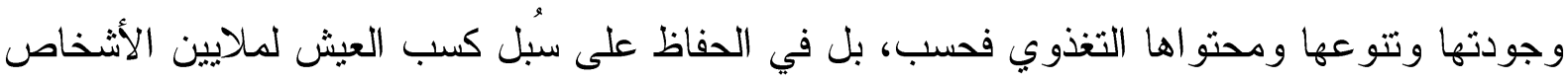

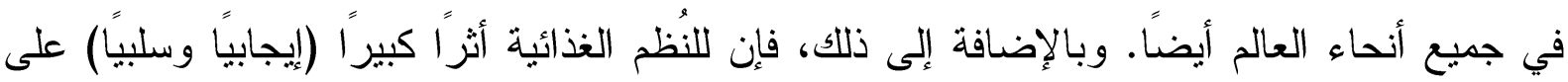

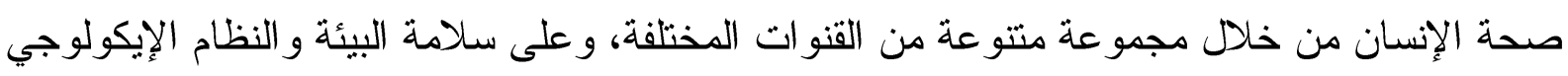

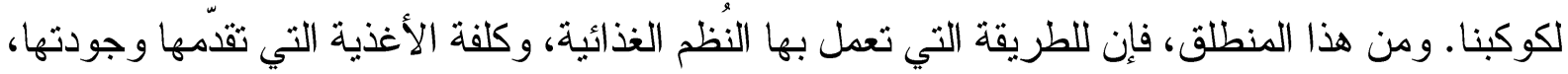

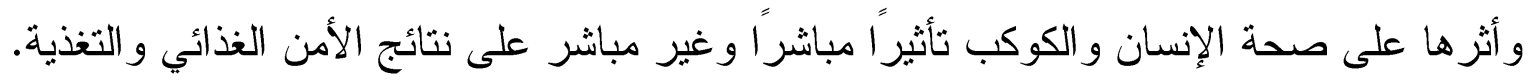

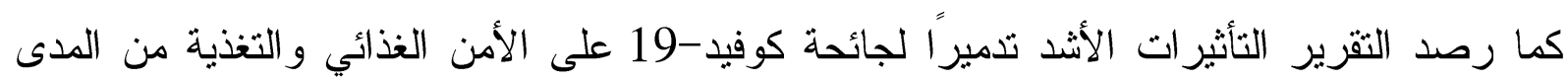
و النطاق غير المسبوقين للانكماش الاقتصادي الذي تسبيت فيه تدابير احتو اء الجائحة (الدو افع الاقتصادية

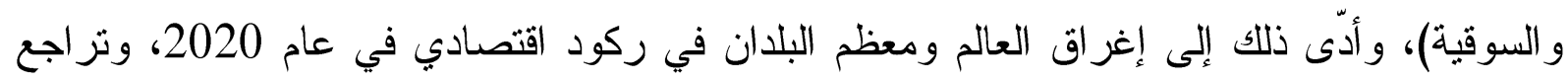

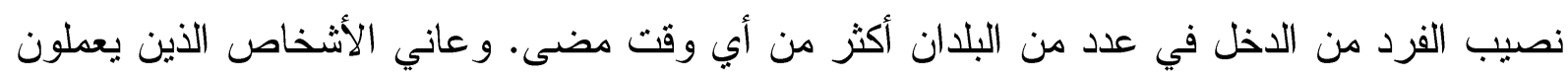

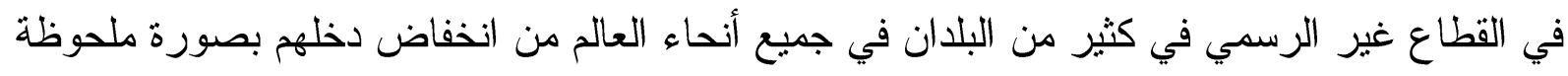

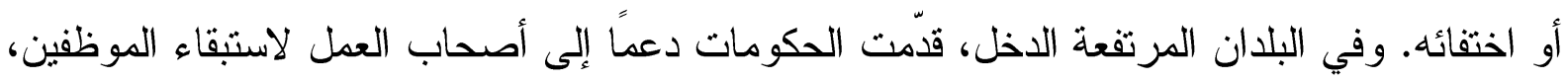
و إن كان ذلك برواتب منخفضة.

\section{ثالثاُ: مسار ات سنة مقترحة للخروج من أزمة الأمن الغذائي و التغذية في العالم}

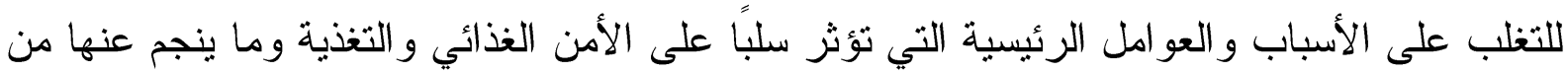

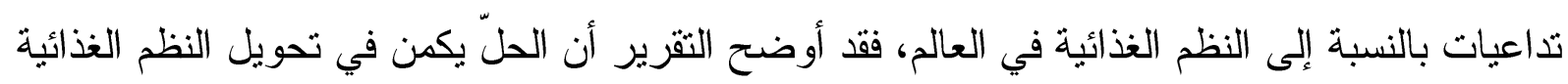
العالمية. وتحقيقًا لهذه الغاية، تم تحديد ستة مسارات، تشمل مجالات السياسات و أهدافها الرئيسية كما هو مبين على النحو التالي: 1. التكامل بين السياسات الإنسانية والإنمائية الخاصة بيناء السلام في المناطق المتأثرة بالنزاعات

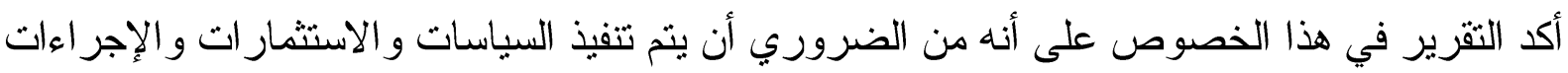

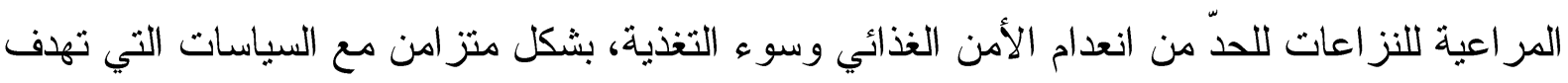


إلى الحدّ من مستويات النز اعات، و أن تتماشى هذه السياسات و الاستثمار ات و الإجر اءات مع جهود التتمية الاجتماعية والاقتصادية وجهود بناء السلام على المدى الطويل. و أثشار التثرير إلى أن بر امج المساعدة الغذائية الطارئة، و الدعم الطارئ لضمان المياه النظيفة، و الخدمات الصحية و الصرف الصحي الجيدة، و التدخلات الهادفة إلى الحفاظ على سبل العيش، تُعدّ من بين الآليات النموذجية للاستجابة للأزمات و الحماية الاجتماعية التي تتفذ لضمان الحدّ الأدنى من مستويات الأمن

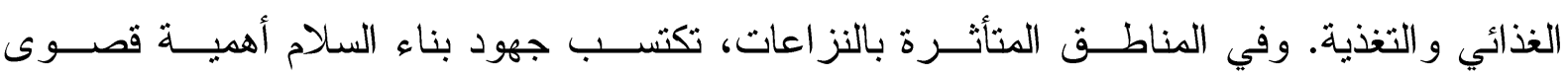
في تحقــق الأمن الغذائي على المدى الطويل وتحســين التغذيــة. و وعلاوة على ذلــــ، ينبغي وضـــع

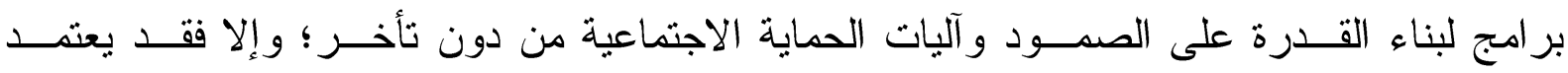

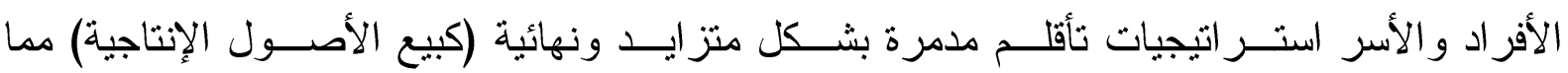
يهذد ســبل كســب العيش و الأمن الغــذائي و التغذية في المستقبل. ويلخص الجدول مجالات السياسات والأهداف الرئيسية لدمج الجهود الإنسانية والإنمائية وجهود بناء السلام في المناطق المتأثرة بالنز اعات.

جدول رقم (1): مجالات السياسات والأهداف لدمج الجهود الإنسانية والإنمائية وبناء السلام في المناطق المتأثرة بالنز اعات

\begin{tabular}{|c|c|}
\hline الأهداف & مجال السياسـات \\
\hline 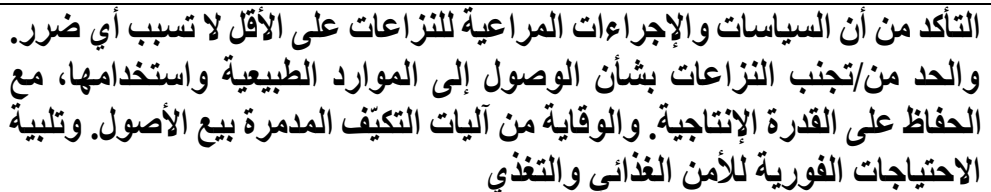 & المرتبطة بـعم سبل كسب العيش العلام \\
\hline والانتعاشل القوي العيش وتدابير الحماية الاجتماعية لضمان الأمن الفذائي والتذذية & 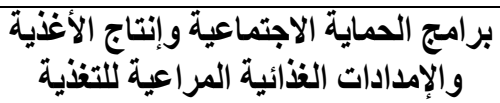 \\
\hline 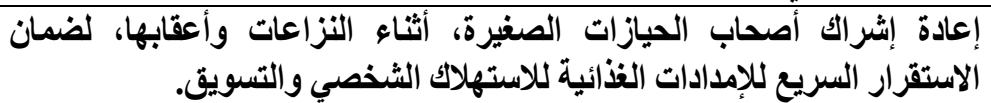 & الحفاظ على الوظائف الرئيسية لسلاسل \\
\hline وتحسيز الثقة و التماسك الاجتماعي لتقليل أوجه علدم اليقين وتعزيز التطلعات الإيجابية & في السياسات بعد انتهاء النزاعات \\
\hline
\end{tabular}

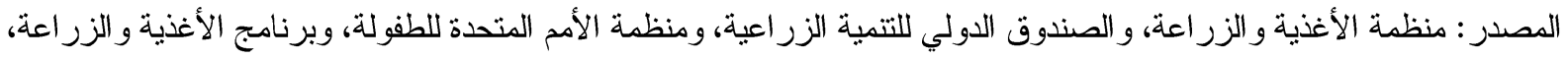

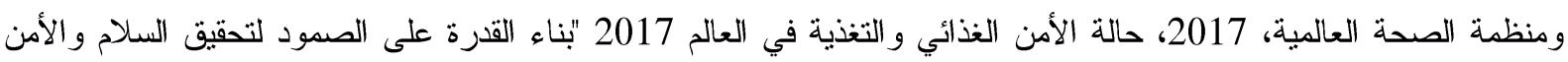
الغذائي". روما.

2. زيادة القدرة على الصمود في وجه تغيّر المناخ في النظم الغذائية و هو الأمر الذي يتطلب تتفيذ سياسات وبر امج القدرة على الصمود في وجه نغيّر المناخ، تكييف الأدوات و التذخلات وتجديدها، مثل: نظم رصد المخاطر والإنذار المبكر؛ والتأهب للطوارئ و الاستجابة لها،

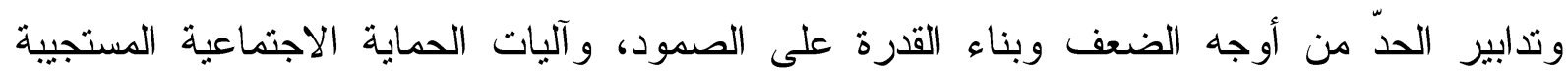


للصدمات، و عمليات نقل المخاطر، و التمويل القائم على التتبؤ، بالإضافة إلى هياكل حوكمة متينة لإدارة المخاطر في التر ابط القائم بين النظم البيئية و الغذائية و الصحية. وقد يتعين على هذه الأدوات أن تقوم على التشريعات لضمان قابلية إنفاذها من ناحية، وحماية الطبيعة، و الإدارة المستدامة لإنتاج الأغذية و إمداداتها، و إصلاح البيئات الطبيعية و إعادة تأهيلها من ناحية أخرى. و لارتباط مخاطر المناخ بالأمن الغذائي في المناطق الريفية بالدول النامية، يتطلب الأمر وضع خطـ لتأمين الأصـــول تشــتهدف على وجه التحديد الأسر الفقيــرة و الضعيفة.

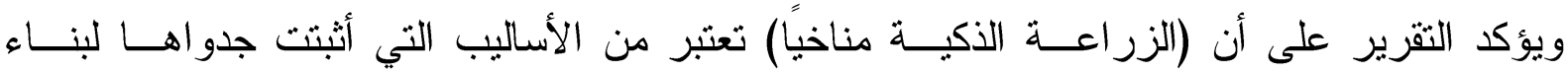
القـدرة على الصمود في وجــه تغير المناخ، و هي تبنـي القــدرة على الصمود بطرق متعــددة من خلال نظم مر اعية للمنــاخ ومفيدة اجنماعياً و اقتصـاديا: فنهج الزر اعة الذكيــة مناخيا يؤدي إلى زيادة الإنتاجية الزر اعية بشــكل مســــام وتحسيــن الدخـلـ، وبنــاء القدرة على الصمود في وجه تغيــر المناخ، وخفض انبعاثات غـــــاز ات الدفيئة. ويلخص الجدول مجالات السياسات و الأهداف الرئيسية لزيادة القدرة على الصدود في وجه تغيّر المناخ عبر النظم الغذائية.

جدول رقم(2): مجالات السياسات و الأهداف الرئيسية لزيادة القدرة على الصمود في وجه تغيّر المناخ عبر النظم الغذائية

\begin{tabular}{|c|c|}
\hline الأهداف & مجال السياسـات \\
\hline 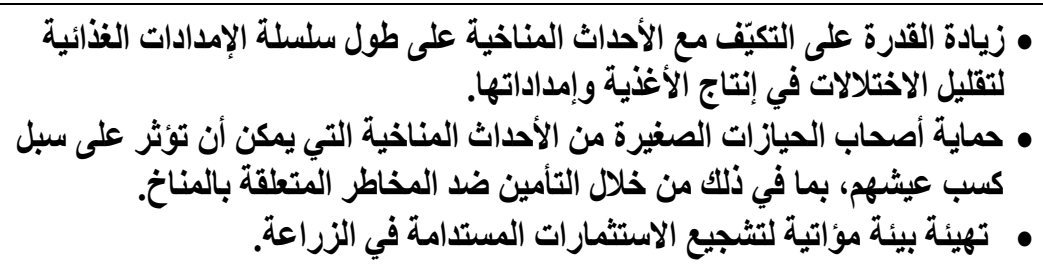 & 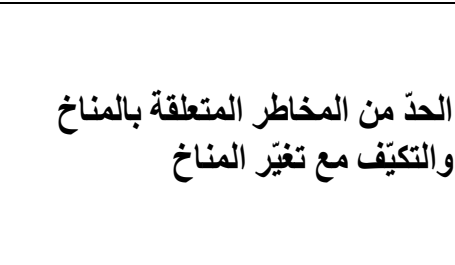 \\
\hline النظدّ من تأثيّير الأخطار المختلفة، بما في ذلك الأحوال المناخية القصوى، في كل من & بالمناخ وللإنذار المبكر لمخاطر المتعلقة \\
\hline 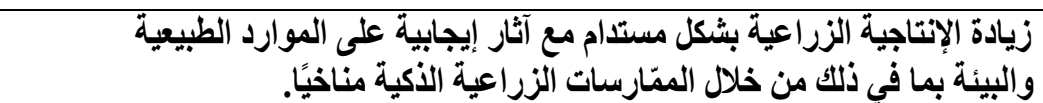 & تالطيينية والوارتها إلى الموارد الإتتاجية \\
\hline
\end{tabular}

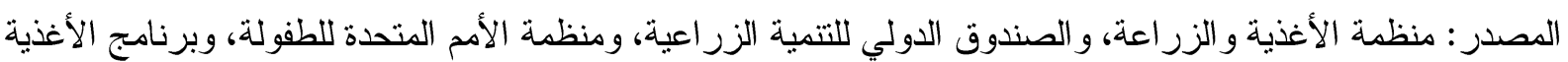
و الزر اعة، ومنظمة الصحة العالمية، 2017، حالة الأمن الغذائي والتغذية في العالم 2017 "بناء القدرة على التهده الصمود لتحقيق السلام و الأمن الغذائي". روماه وماهـ

\section{3. تعزيز قدرة الفئات السكانية الأشد ضعفًا على الصمود في وجه الصعوبات الاقتصادية} مما لا شك فيه أن التذابير المتخذة خلال تفشي جائحة كوفيد-19 سواء كانت هذه التدابير برامج للمساعدات الاجنماعية، أو التوظف، أو التأمين الاجتماعي، أظهـرت أهمية بناء القــدرة على الصمود في وجه المحن الاقتصادية، وبات من الواضح أنه من الأهمية بمكان وضع السياسات الاقتصادية و الاجتماعية والتشريعات وغير ذلك من التدابير، قبل حدوث حالات التباطؤ والانكماش الاقتصاديين 
بفترة طويلة، حيث أن هذه التدابير مصمَّة لمو اجهة آثار الدورات الاقتصادية السلبية عند حدوثها، ولا سيما بالنسبة إلى فئات السكان الأكثر ضعفًا، وللحفاظ على إمكانية الحصول على الأغذية المغذّية و الأنماط الغذائية الصحية. ويشير التثرير أنه على المدى القريب، يجب أن تتضمن هذه السياسات و القوانين والاستثمارات آليات

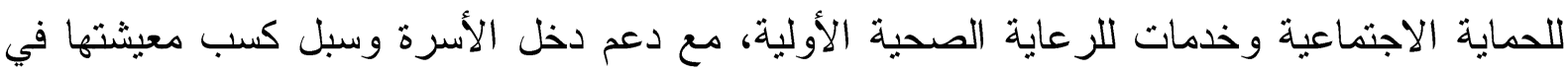

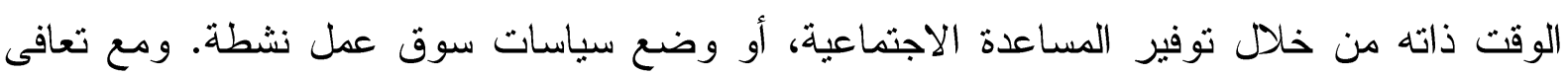
البلدان من آثار الجائحة، فأنه من الأهمية الحفاظ على مستويات كافية من الإنفاق العام على نظم الحماعه الحماية

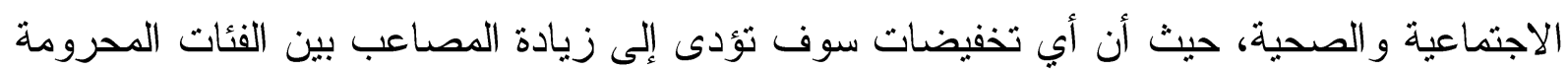

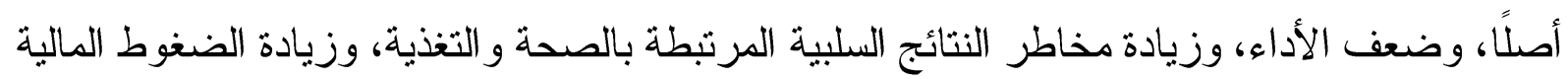
وتقويض مكاسب التتمية. و على المدى المتوسط يثير التقرير إلى أنه ينبغي إضفاء الطابع المؤسسي على هذه السياسات كجزء

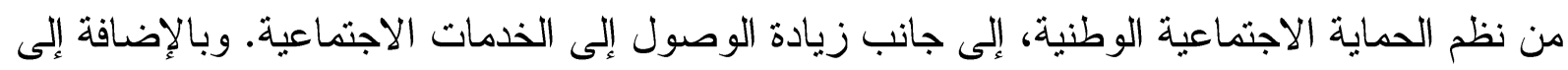

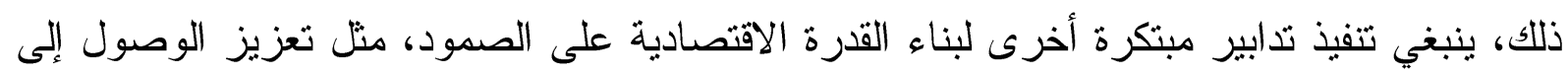

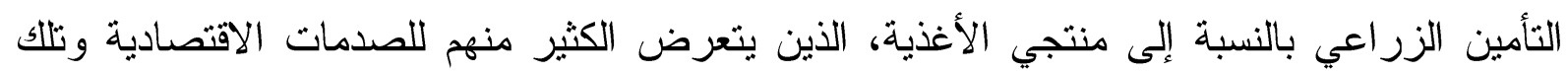

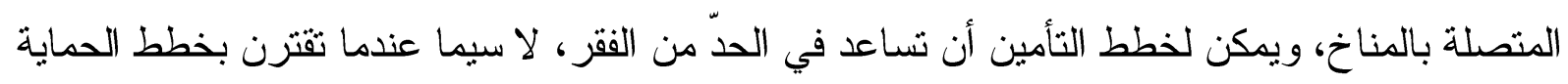
الاجنماعية.

ويلخص الجدول مجالات السياسات و الأهداف الرئيسية لتعزيز قدرة الفئات الأكثر ضعفًا على الصمود في وجه المحن الاقتصادية. جدول رقم (3): مجالات السياسات والأهداف الرئيسية لتعزيز قدرة الفئات

الأكثر ضعفًا على الصمود اقتصادياً

\begin{tabular}{|c|c|}
\hline الأهداف & مجال السياسات \\
\hline تحلسيلة الإمدادات الذذائية لأصحاب الحيازات الصغيرة والجهات الفاعلة الأخرى في & 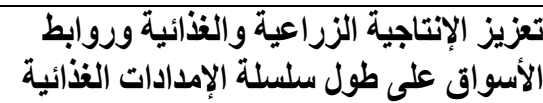 \\
\hline 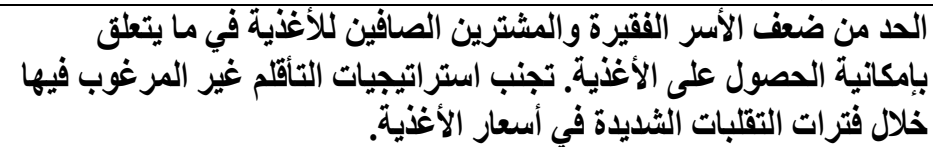 & 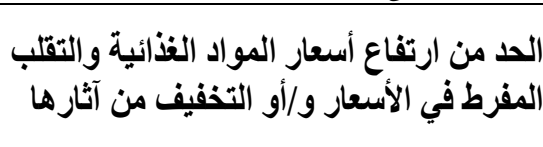 \\
\hline 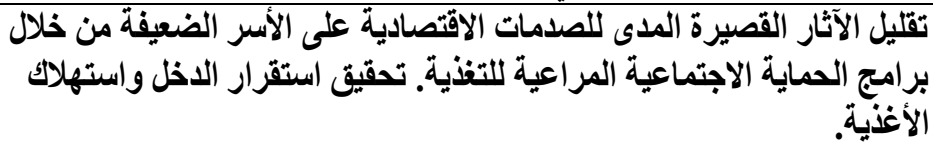 & عية العل وتوسيع نطاق برامج \\
\hline
\end{tabular}

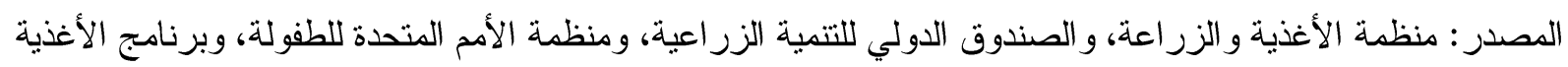

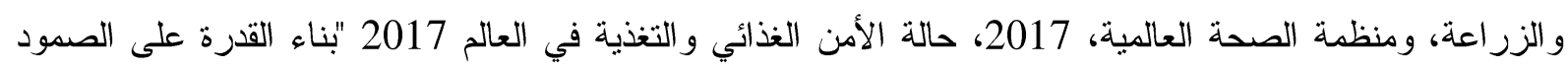
لتحقيق السلام و الأمن الغذائي". روما. 
4. التخلات على طول سلاسل الإمدادات الغذائية لخفض تكلفة الأغذية المغنية يؤكد التقرير على أهمية التخلل على طول سلاسل الإمدادات الغذائية لزيادة نو افر الأغذية الآمنة و المغذية وخفض تكلفتها، كوسيلة لزيادة القدرة على تحمل تكلفة الأنماط الغذائية الصحية. ويقتضي هذا المسار وضع مجموعة منسقة من السياسات والاستثار ات من الإنتاج إلى الاستهلاكك، تهدف إلى تحقيق مكاسب في الكفاءة، والحد من الفاقد والمهدر من الأغذية للمساعدة على تحقيق هذه الأهداف، وينبغي لهذه الحو افز أن تشجع على تتويع الإنتاج في قطاعي الأغذية و الزر اعة للإتجاه نحو

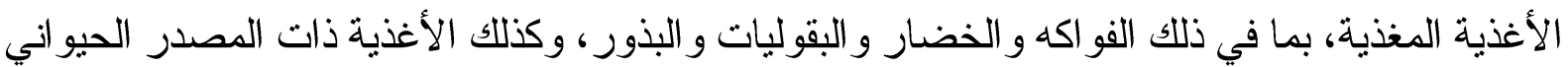

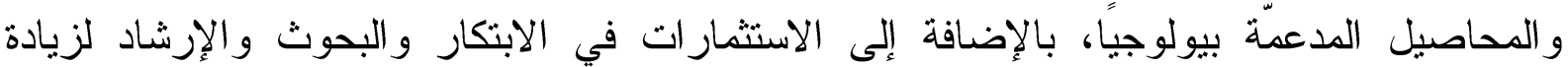

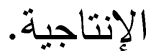

وفي أماكن أخرى من سلسلة الإمداد، يمكن تحسين الجودة الغذائية للمنتجات الغذائية والمشروبات عن

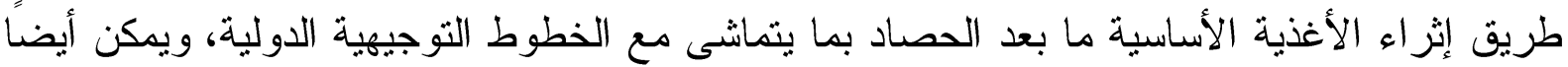

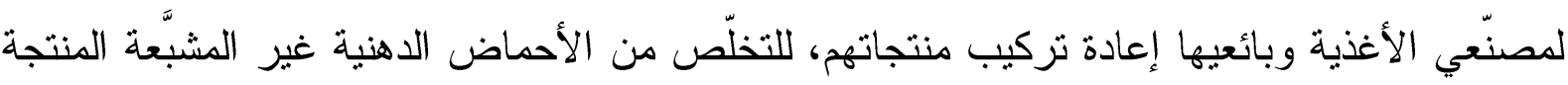

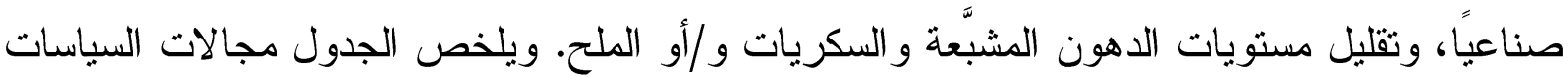
و الأهداف الرئيسية للتنخل على طول سلاسل الإمدادات الغذائية لخفض كلفة الأغذية المغذية. جدول رقم (4): مجالات السياسات والأهداف الرئيسية للندخل

تعبر سلاسل الإمدادات الغذائية لخفض كلفة الأغذية المغذية

\begin{tabular}{|c|c|}
\hline الأهداف & مجال السياسات \\
\hline زيادة إمدادات الأغذية الآمنة والمغذية، وخفض كلفتها. & زيادة الاستثمارات من أجل قطاع زراعي \\
\hline 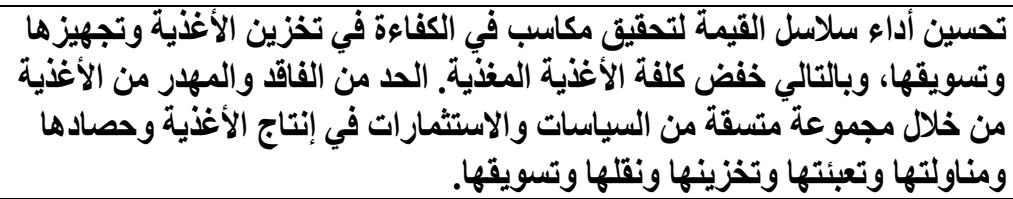 & زيادة كفاءة سلاسل القيمة الغذائية \\
\hline 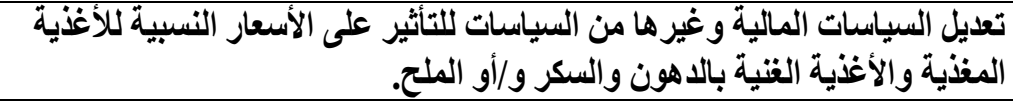 & تهيئة بيئة تروجة للأغذية على طول الإمدادات \\
\hline زيادة الإمدادات بالأغذية المدعمة كجزء من برنامج لمعاجلة نقص المغذيات الدقيقة & 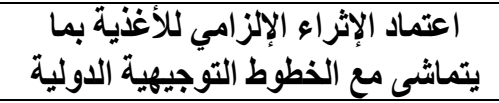 \\
\hline زليقادة إنتاج الأغذية ذات المحتوى العالي من المغذيات الدقيقة لمعاجلة نقص المظذيات & 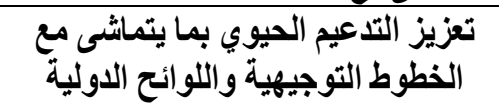 \\
\hline
\end{tabular}

المصدر : منظمة الأغذية و الزر اعة، والصندوق الدولي للتنمية الزر اعية، ومنظمة الأمم المتحدة للطفولة، وبرنامج الأغذية

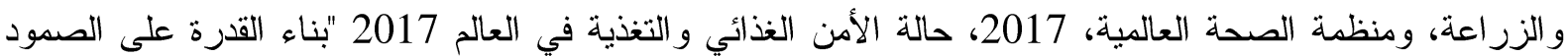

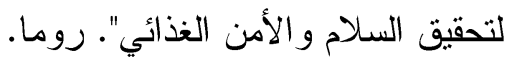


5. التصدي للفقر وأوجه انعدام المساواة الهيكلية مع الحرص على أن تكون التخلات شاملة ومراعية لمصالح الفقراء

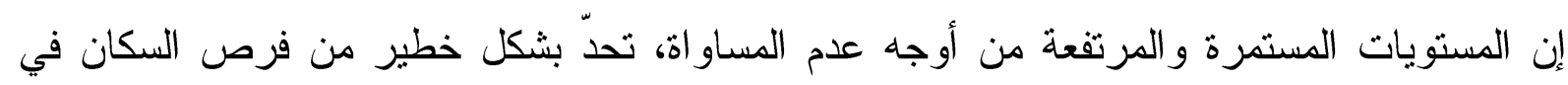

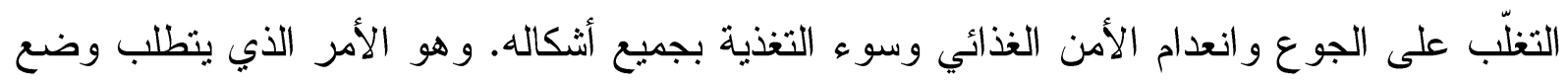

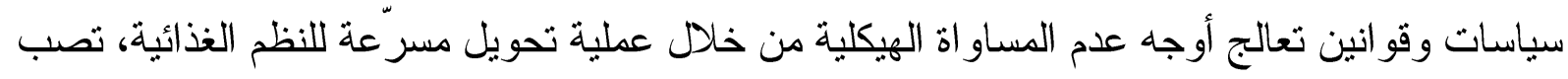

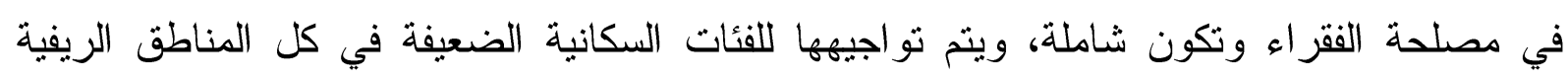
و الحضرية.

و أثار الثقرير إلى العديد من المبادرات في هذا الصدد منها على سبيل المثال، مبادرة منتجات الثر اكة من أجل التنمية المستدامة في المناطق الجبلية، والتي استهدفت تعزيز قدرة السكان الذين يعيشون في لهي المناطق الجبلية على الصمود وتحسين اقتصاداتهم ونظمهم البيئية.

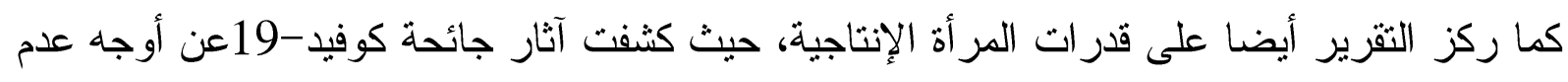

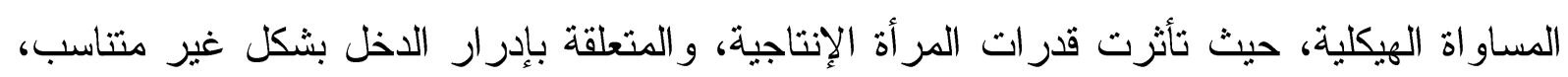

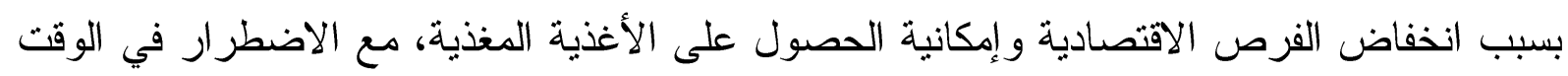

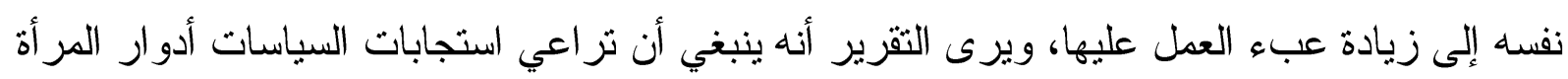

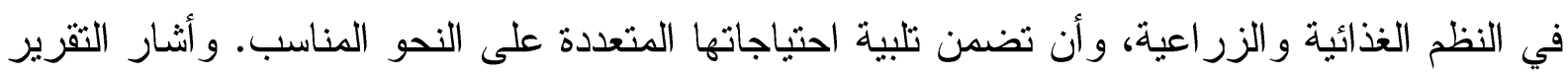

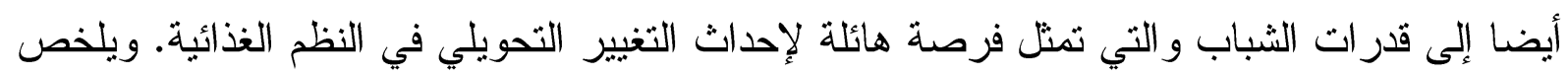

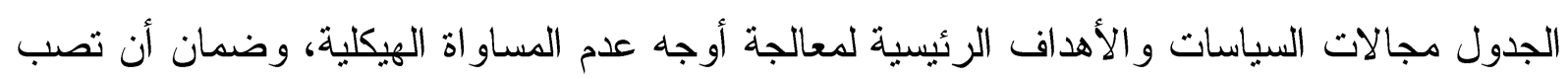
التدخلات في مصلحة الفقر اءو وأن تكون شاملة للجميع. جدول رقم (5): مجالات السياسات والأهداف الرئيسية لمعالجة أوجه عدم المساواة الهيكلية، وضمان توجيه التخخلات في مصلحة الفقراء وأن تكون شاملة للجميع

\begin{tabular}{|c|c|}
\hline الأهداف & مجال السياسات \\
\hline 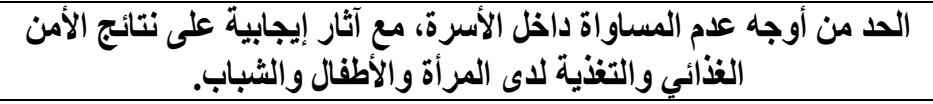 & تمكين الفئات الضعيفة والمهشة تاريخيًا \\
\hline 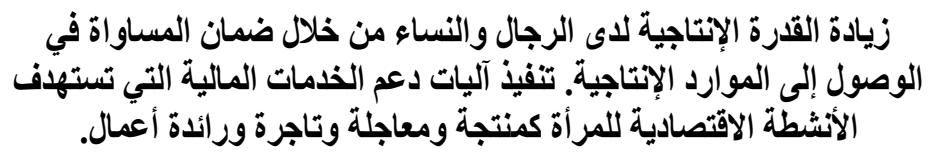 & 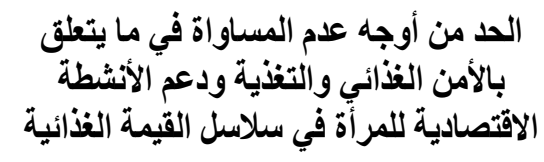 \\
\hline 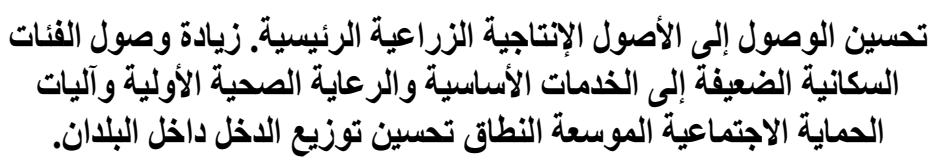 & 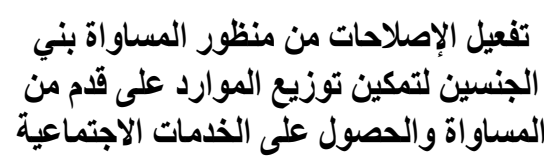 \\
\hline
\end{tabular}

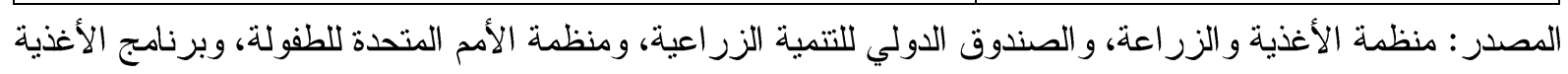

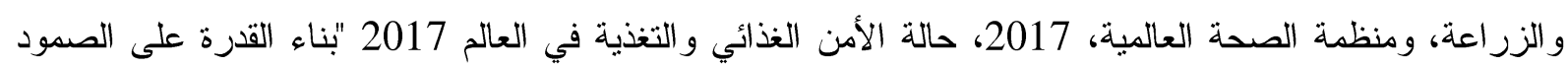
لتحقيق السلام و الأمن الغذائي". روما. 
6. نعزيز بيئات الأغنية وتغيير سلوك المستهكين لتعزيز الأنماط الغذائية ذات الآثار الإيجابية على صحة الإنسان

و البيئة

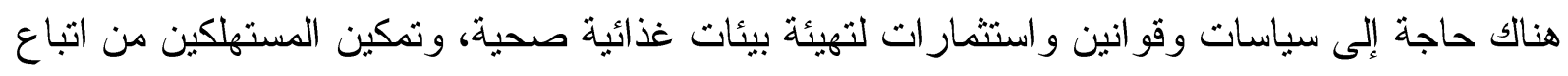

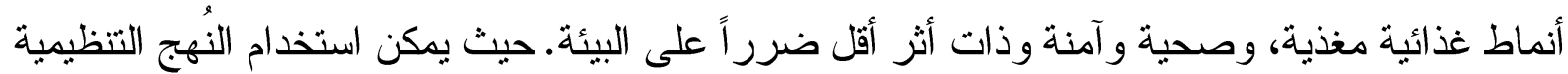

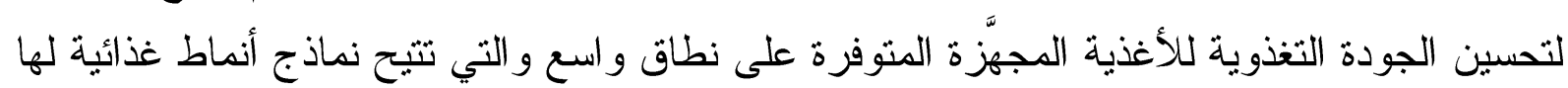

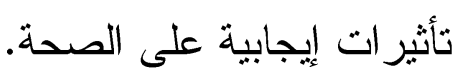
و أشار التقرير إلى العديد من النُهج التنظيمية في هذا الصدد منها على سبيل المثال:

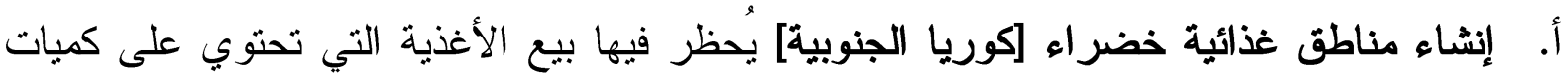
عالية من الطاقة وحد أدنى من القيمة التخذوية بما في ذلك الوجبات التوريات الغذائية السريعة.

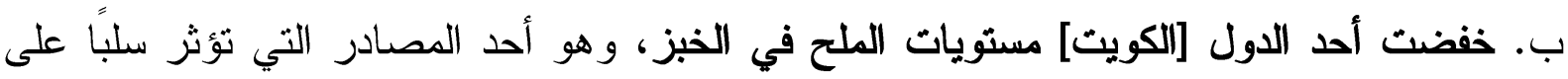

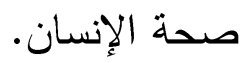

ت. رفعت أحد الدول [بيرو] الضرائب المفروضة على المشروبات المحلّة بالسكر لخطورتها على الصحة.

ويلخص الجدول مجالات السياسات والأهداف الرئيسية، بما في ذلك القو انين و اللو ائح ذات الصلة بتعزيز بيئات الأغذية وتغيير سلوك المستهلك لتعزيز الأنماط الغذائية ذات الآثار الإيجابية على صحة الإنئ الإنسان و البيئة

جدول رقم (6): مجالات السياسات والأهداف الرئيسية لتعزيز بيئات الأغذية

وتغيير سلوك المستهلك لتعزيز نماذج الأنماط الغذائية ذات الآثار الإيجابية على صحة الإنسان والبيئة

\begin{tabular}{|c|c|}
\hline الأهداف & مجال السياسات \\
\hline 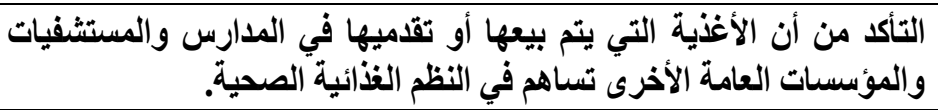 & تنفيذ سياسات المثتريات العامة للأغذية الصحية \\
\hline تكلفزيز دور التجارة لزيادة توافر النظم الذأيَّة الصحية والقدرة على تحمل & 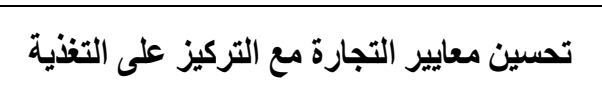 \\
\hline 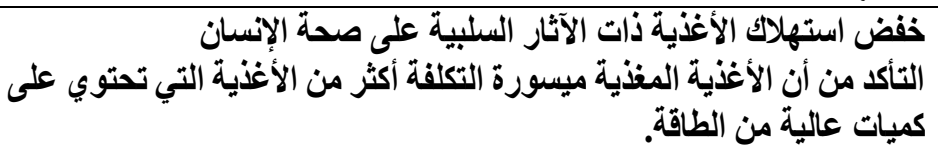 & 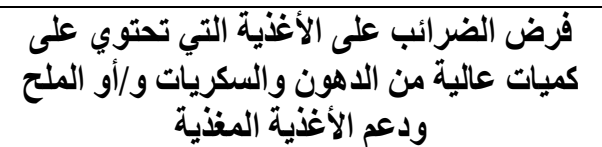 \\
\hline 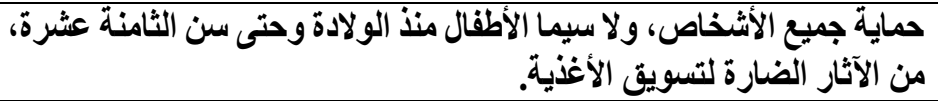 & خاصة بتسويق المواد الذذائية \\
\hline التخلص من الاهون غير المشبعة الصناعية من سلسلة الإمدادات الذذائية. & تنظيم الدهون غير المشبعة الصناعية \\
\hline 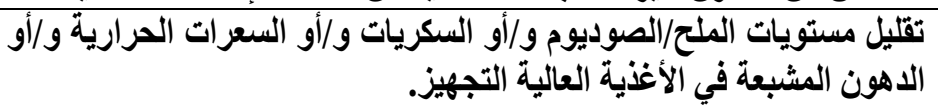 & الذأئية والمشروبات \\
\hline
\end{tabular}

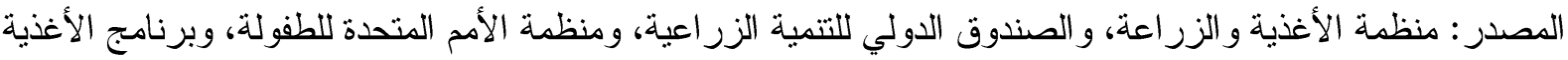

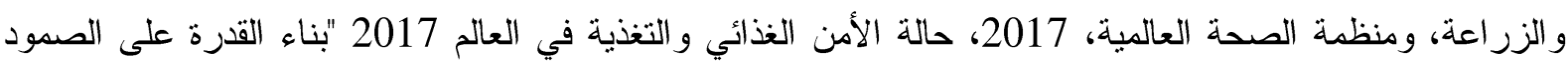

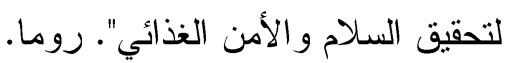


رابعاً: أطر وخطوات ومنطلبات تحويل النظم الغذائية من أجل تحقيق الأمن الغذائي وتحسين التغذية وتوفير أنماط غذائية صحية ميسورة الكلفة للجميع في العالم يوضّح الثكل التالي، خطوات تحويل النظم الغذائية والتي نعالج الأسباب والعوامل الرئيسية لانعدام

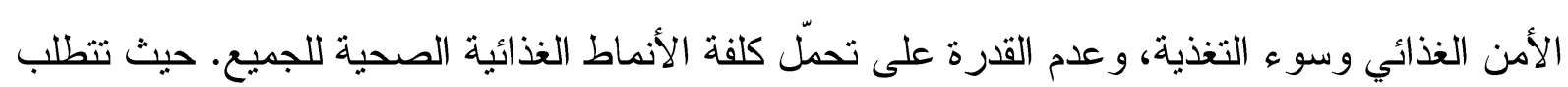
العملية ما يلي: 1. - إجر اء تحليل متعمثّ للحالة محدد السياق. 2. صباغة حافظات متّسقة مشتركة بين القطاعات من السياسات والاستثار ات و التشريعات، بما في ذلك العو امل المسرّعة التي تحفز العمليات التحويلية. 3. تتفذ هذه الحافظات مع إجر اء رصد وتثييم ملائمين، فضلًا عن وضع آليات للمساءلة. شكل رقم (1): خطوات تحويل النظم الغذائية في العالم

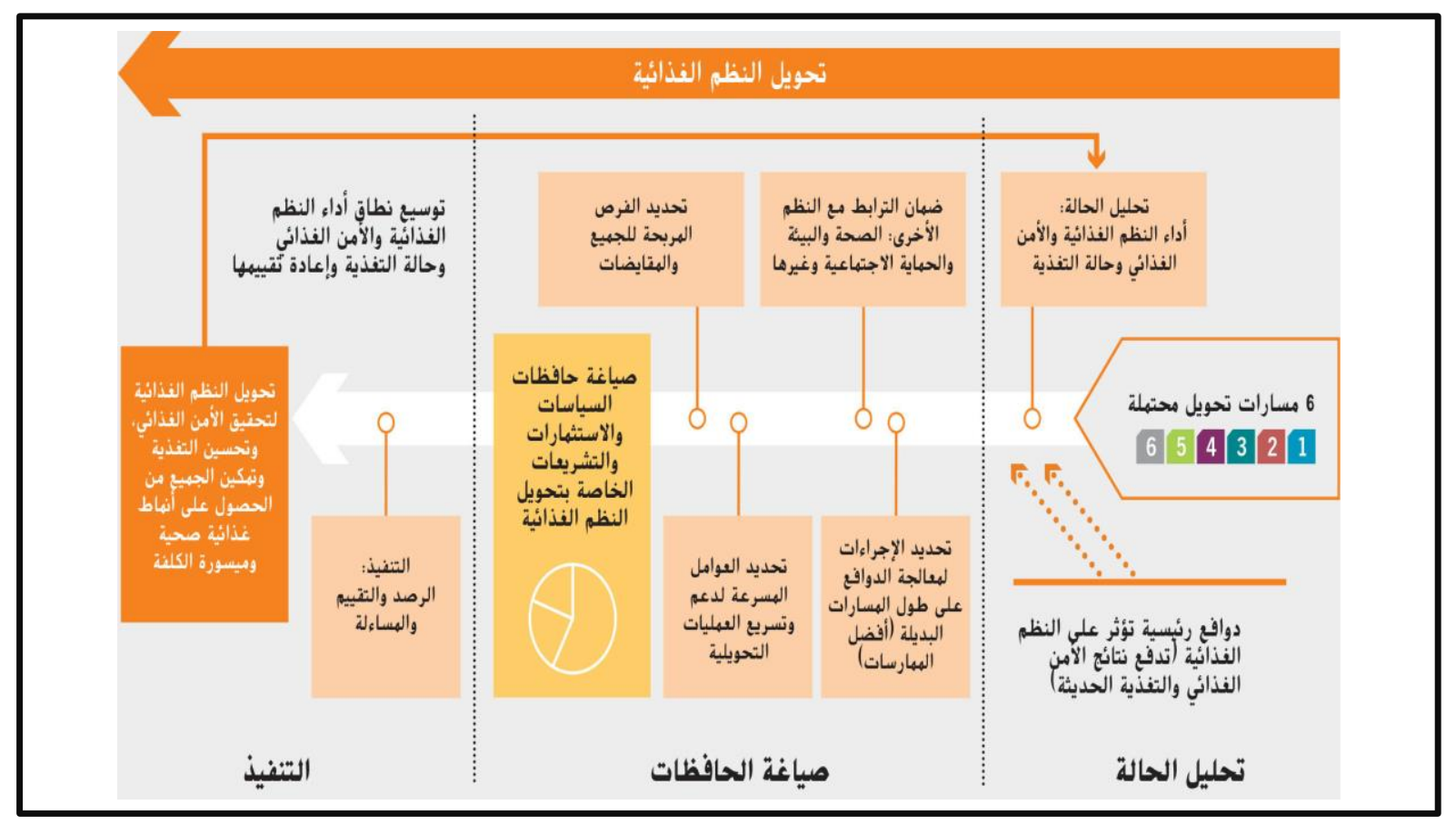

المصدر : منظمة الأمم المتحدة للأغذية و الزراعة وآخرون (2021). حالة الأمن الغذائي و التغذية في العالم: تحويل النظم

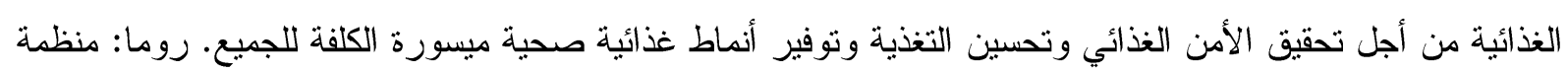
الأغذية و الزز اعة. 
ونلقى مزيد من الأضواء فيما يلي على أبرز الأطر والخطوات والمنطلبات: 1 1بناء حافظات متّسقة من السياسات والاستثمار مات

تبدأ صياغة حافظات شاملة من السياسات و الاستثمار ات بتحليل حالة الأمن الغذائي و التغذية للحصول على فهم متعمّق لوضع الدولة، بما في ذلك طبيعة وكثافة الدو افع الرئيسية التي تثؤثر على النظم الغذائية

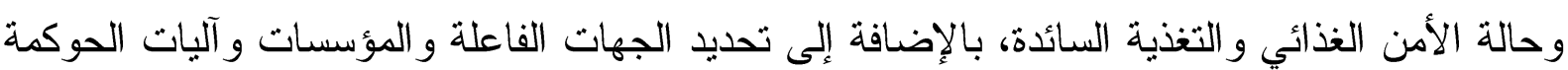
ذات الصلة. ويمّكن تحليل الحالة من تقييم أي مجموعة من المسارات لتحويل النظم الغذائية هي الأكثر ملاءمة، بالنظر إلى الطريقة الني أثرت بها الدوافع الرئيسية لانعدام الأمن الغذائي وسوء التخذية عليها، وما هي تدابير السياسات والاستثمار ات الأكثر ملاءمة لنكون جزءًا من الحافظة.

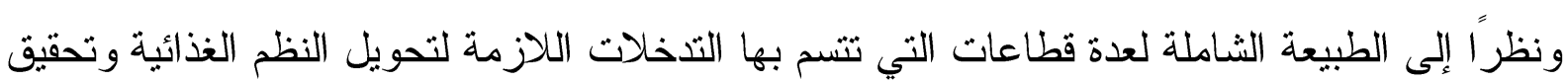
الأمن الغذائي وتحسين التغذية، فإن تحقيق الاتساق في مجال السياسات و الاستثمار ات بين النظم الغذائية الزراعية ونظم البيئة والنظم الصحية ونظم الحماية الاجتماعية والنظم الأخرى، مثل التعليم والطاقة و التجارة و التمويل، أمر ضروري لإحداث التغيير التحويلي الفعال. و الاتساق مطلوب ليس من أجل الصياغة الفعالة فحسب، بل من أجل التتفيذ الفعال والمسرّع للحافظات أيضًا، و الأهم من ذلك، فبصرف النظر عن الوصول إلى الموارد الإنتاجية والمالية، ينطلب التغيير

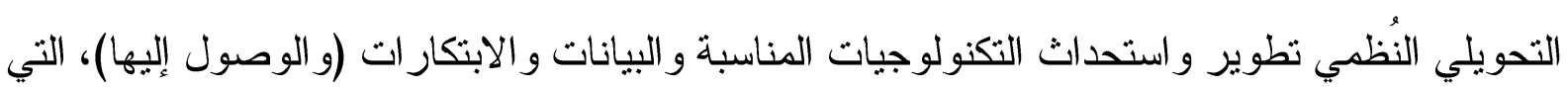
يشار إليها بالعو امل المسرّعة، لتحفيز العمليات التحويلية. 
شكل رقم (2): المكونات والعناصر الرئيسة لحافظة السياسات والاستثمارات لتحويل النظم الغذائية

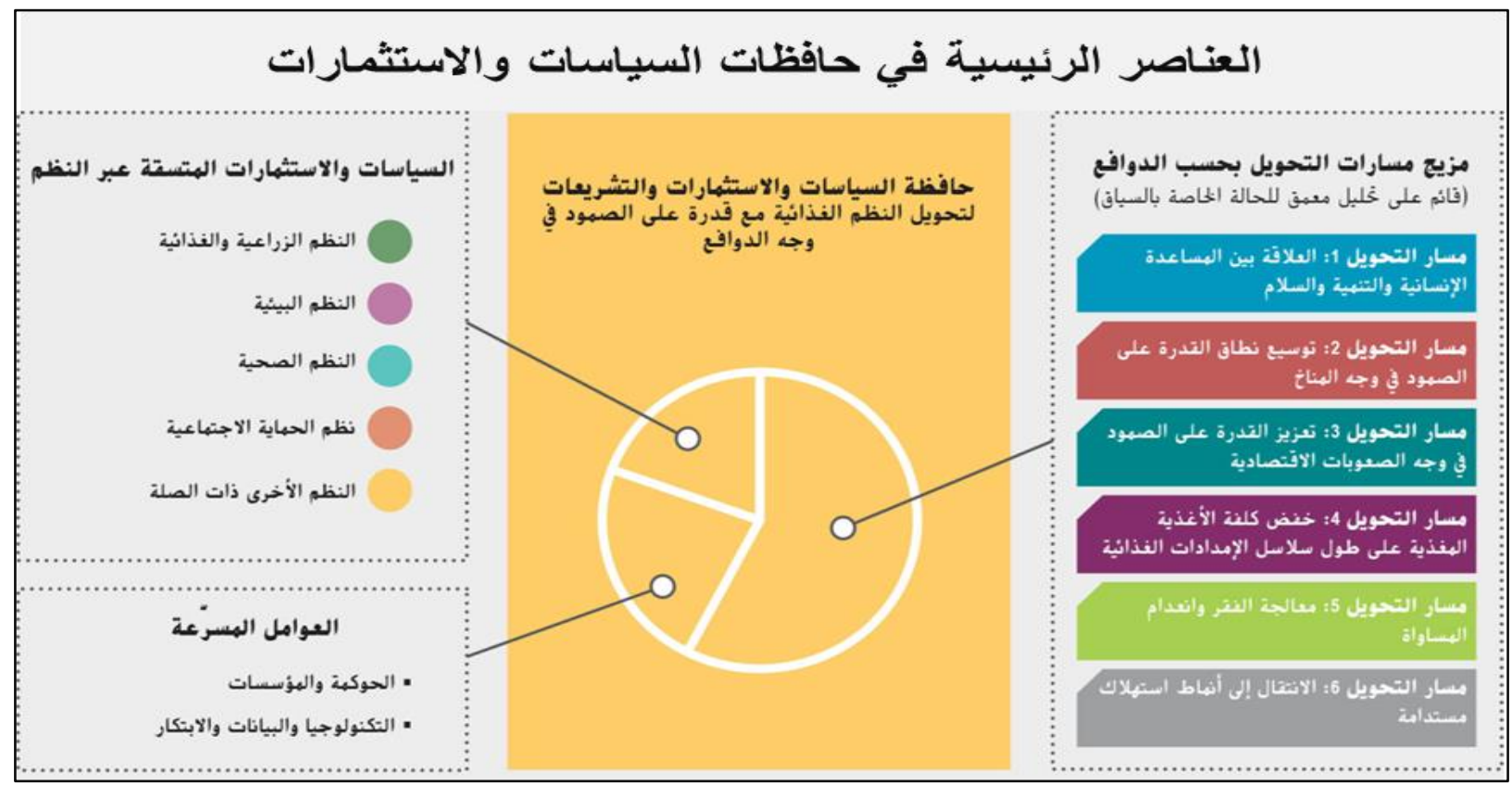

المصدر : منظمة الأمم المتحدة للأغذية و الزر اعة و آخرون (2021). حالة الأمن الغذائي و التخذية في العالم: تحويل النظم

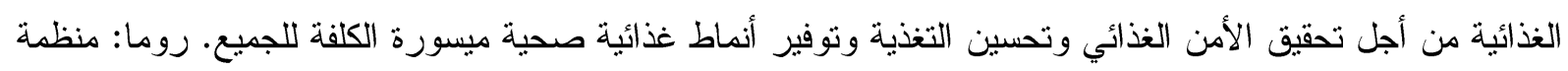

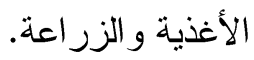

2.اتساق سياسات واستثمارات النظم الغذائية مع النظم الأخرى ذات الصلة يعتمد الأداء العام للنظم الغذائية على انساقها وتفاعلها مع عدة نظم أخرى، بما فيها، النظم الغذائية و الزر اعية، بالإضافة إلى نظم الحماية البيئية و النظم الصحية والاجتماعية. وتؤدي النظم الأخرى دورًا حاسمًا على طول النظام الغذائي، بدءًا من توفير المعارف والمهارات اللازمة في ما يتعلق بإنتاج

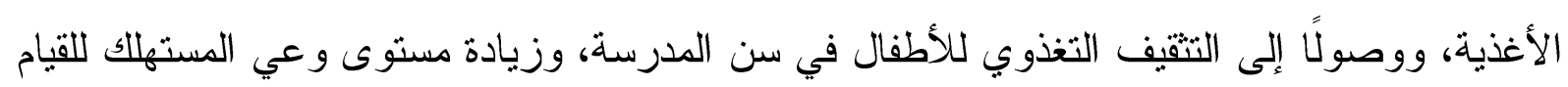
بخيار ات أفضل. وبالنظر إلى العلاقات المتبادلة القائمة فيما بين النظم، تظهر النظم الغذائية كمجال مشترك -كما يوضح الثكل- محتمل لتعزيز المنافع المشتركة لمجموعة من أهداف السياسات بكفاءة وفعالية، وبالتالي، فبصرف النظر عن تحديد حافظات السياسات والاستثمارات لتحويل النظم الغذائية نفسها، فأن هناك حاجة إلى تحقيق اتساق السياسات مع النظم الأخرى التي تدعم الاستدامة لهذه النظم الغذائية على الددى الطويل. 


\section{شكل رقم (3): الترابطات والتكاملات التفاعلية بين النظم الغذائية وغير ها من النظم}

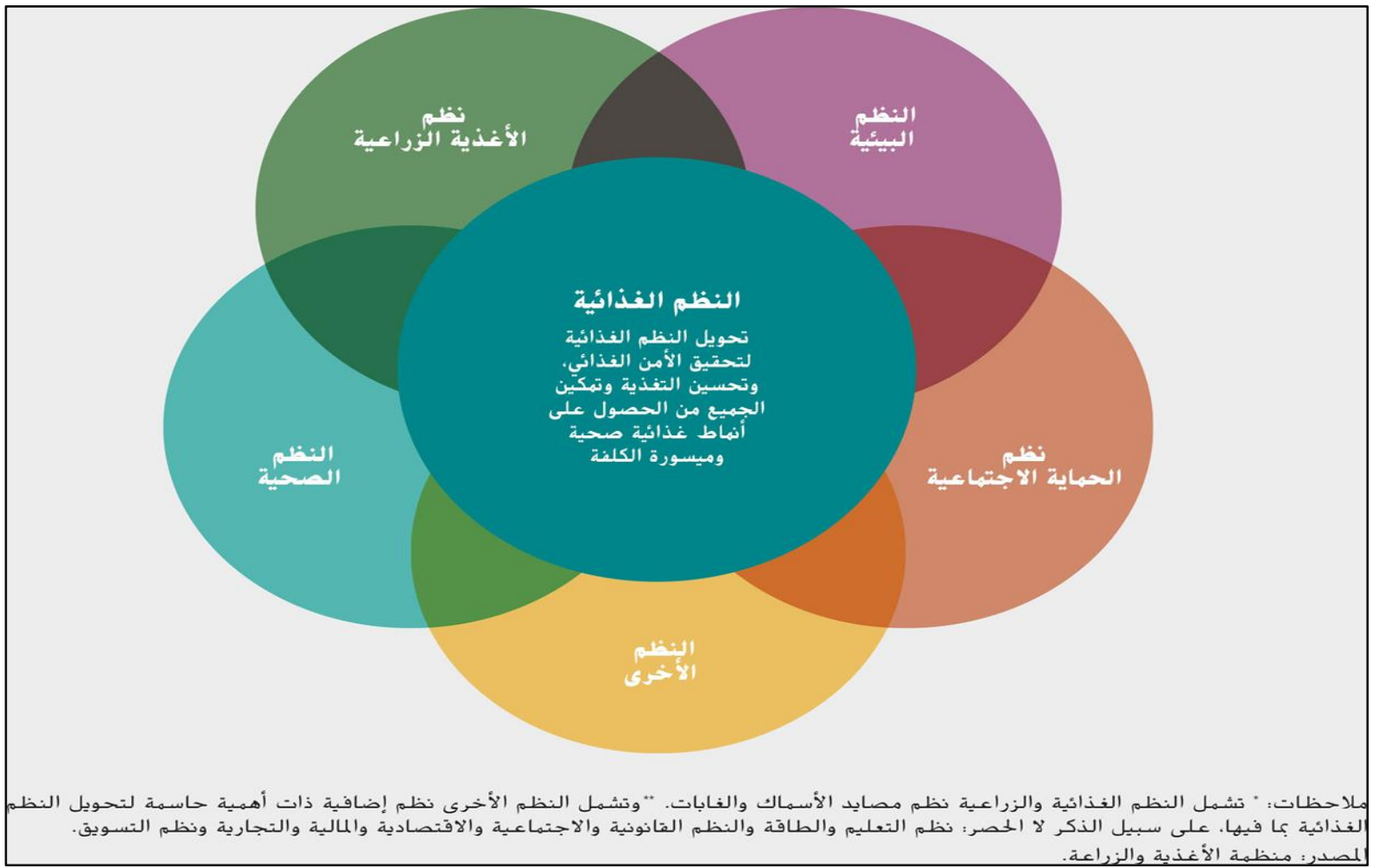

المصدر : منظمة الأمم المتحدة للأغذية و الزر اعة و آخرون (2021). حالة الأمن الغذائي و التغذية في العالم: تحويل النظم الغذائة من أجل تحقيق الأمن الغذائي وتحسين التغذية وتوفير أنماط غذائية صحية ميسورة الكلفة للجميع. روما: منظمة الأغذية و الزر اعة.

وتشمل النظم الغذائية و الزر اعية كامل نطاق الجهات الفاعلة في العملية الإنتاجية وأنشطتها المترابطة ذات القيمة المضافة. بداية من مر احل الإنتاج الأولي للمنتجات الغذائية وغير الغذائية في قطاعات الزر اعة ومصايد الأسماك و الغابات، وكذلك تخزين الأغذية وتجميعها ونقلها وتجهيزها وتوزيعها وتسويقها و التخلّص منها و استهلاكها، وتثفاعل النظم الغذائية و الزر اعية مع سلاسل الإمداد غير الغذائية من خلال شر اء المدخلات الزر اعية وعن طريق توفير مدخلات وسيطة لإنتاج السلع غير الغذائية. وتوفر النظم البيئية، الظروف البيئية والمغذيّات الضرورية في قطاعات الزراعة ومصايد الأسماك و الغابات لإنتاج الأغذية. ومن ناحية أخرى، تؤثر نظم الإنتاج الغذائي و الزراعي على البيئة بطرق متعددة، بما في ذلك من خلال تأثثرها على التتوع البيولوجي، وجودة التربة و المباه، وصحة الحيوان و النباتات، و انبعاثات غازات الدفيئة، فضلًا عن الفاقد و المهدر من الأغذية. وبالتالي، هناك اعتراف مثز ايد بالحاجة إلى نماذج إنتاج و إمدادات إيجابية للطبيعة، "تتتج أكثر بمو ارد أقل" لضمان إمدادات غذائية مغذية كافية لعدد سكان العالم المتز ايد على مدى العقود القادمة. 
وفي السياق المحدد لتحويل النظم الغذائية، تكتسب نظم الطاقة أهمية حاسمة لضمان زيادة الإنتاجية، و تقليل الفاقد و المهدر من الأغذية، وقد تساعد زيادة كفاءة الطاقة في خفض تكلفة الأغذية الآمنة و المغذية. كما تُعد النظم الصحية وخدماتها أمورًا حيوية لضمان قدرة السكان على استهلاك الأغذية و الاستفادة من المغذيات اللازمة لصحتهم ورفاههم.

ويشير النظر بشكل أكثر تمعنًا في الر ابط القائم بين الأغذية و الصحة إلى أن الأنماط الغذائية غير الصحية

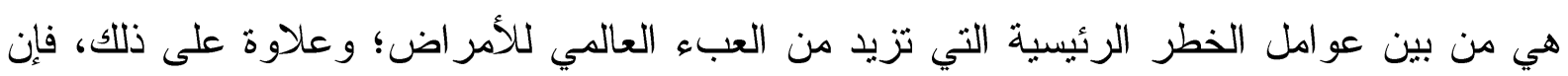
الآثار الصحية السلبية المرتبطة بالأنماط الغذائية الرديئة الجودة جسيمة (الأنماط التي تحتوي على أغذية ذات نسبة عالية جداً من الدهون والسكريات و /أو الملح، وحد أدنى من القيمة التغذوية، ومستويات

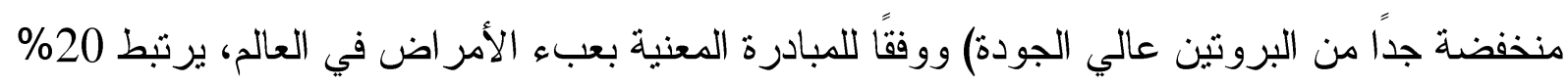
من الوفيات المبكرة في جميع أنحاء العالم بنمط غذائي رديء الجودة. تمثلّ نظم الحماية الاجنماعية مجموعة من السياسات والبر امج، غالباً ما تستند إلى تشريعات قابلة للتفبذ، تعالج مو اطن الضعف الاقتصادية و البيئية والاجتماعية للفقر وانعدام الأمن الغذائي وسوء التغذية من خلال:

أ. دعم دخل الأسرة وسبل كسب عيشها للفئات الأشد فقرًا وضعفًا من خلال مبادر ات المساعدة الاجتماعية (بر امج التحويلات النقاية التي توفر الدعم لتلبية الاحتياجات الأكثر إلحاحًا والتي تمكِّ الأسر من الاستثمار في أنشطتها الإنتاجية) و غيرها من المبادرات. ب. تحسين الوصول إلى الأنماط الغذائية الصحية و الميسورة التكلفة من خلال بر امج الأغذية و التغذية

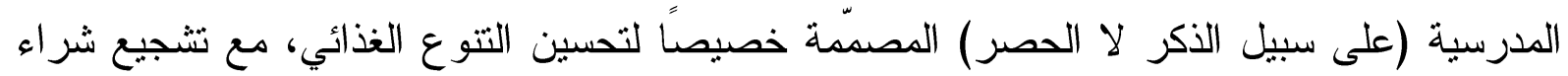
الأغذية الطازجة من المنتجين المحليين. ويمكن للتحويلات العينية، لا سيما في الأماكن التي لا تعمل فيها أسواق المواد الغذائية بشكل جيد، زيادة الحصول على الأغذية المغذية، بالإضافة إلى الإعانات الغذائية، لا سيما تلك التي ثركز على الأغذية المغذية وتستهدف الفئات الأكثر ضعفًا.

\section{3.دور العوامل المسرعة و المحفزة في تحويل النظم الغذائية}

يتطلب التففذ الفعال و الكفو ء لحافظات السياسات و الاستثمار ات بيئة تمكينية مؤلفة من آليات ومؤسسات للحوكمة تسهّل التشاور عبر القطاعات وبين أصحاب المصلحة الرئيسيين، وفي الوقت نفسه، يُعد توسيع نطاق تو افر التكنولوجيات والبيانات و الحلول المبتكرة أمرًا أساسيًا لتسريع وتيرة العمليات التحويلية، و غالبًا ما تُعزى عمليات تحويل النظم الغذائية بالأساس إلى الابتكار ات التكنولوجية، مع تجاهل أهمية الظروف الاجنماعية والسياسية في تمكين تتفيذها، والأهم من ذلك، هناك حاجة إلى مجموعة و اسعة دن الابتكار ات المؤسسية والاجتماعية و الثقافية وفي مجال السياسات لتمكين تطبيق تكنولوجيات 
و ابتكار ات جديدة لإحداث تحوّل للنظم الغذائية، و اعثمادها. ونلقى الضوء فيما يلي على أهم فئتين من العو امل المسرّعة و المحفزة لتحولّ النظم الغذائية: أ.الحوكمة والمؤسسات: ثم الاعتر اف بشكل مثز ايد بأهمية أنشاء آلية حوكمة مشتركة بين المؤسسات الفعالة في تتفيذ سياسات النظم الغذائية المتسقة والمتكاملة، خاصة بعد أزمة أسعار الأغذية العالمية، و هناك الكثير من الآليات القائمة على المستويات العالمية و الوطنية، وكلّها تهدف إلى ضمان التشاور و التعاون المناسبين عبر القطاعات وبين الجهات الفاعلة الرئيسية. و على المستويات الوطنية، من الأفضل وضع آليات الحوكمة الأكثر فاعلية لتسيق الإجراءات المتعددة القطاعات عبر النظم، على أعلى المستويات الوز ارية بالتشاور الوثيق مع الوزارات و المؤسسات القطاعية. و الأهم من ذلك، ينبغي لآليات

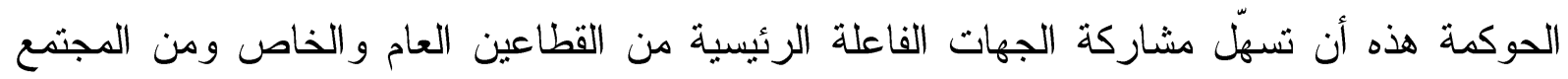
المدني.

ب. التكنولوجيا و البيانات والابتكار: تمثّل التكنولوجيا و البيانات و الابتكار ، مجموعة أساسية من العو امل المسرعة و المحفزة للتغيير التحويلي في النظم الغذائية. وكانت الابتكار ات التكنولوجية خلال القرن الماضي مسؤولة عن التحسينات الأساسية المسجلة في إنتاج الأغذية ومعالجتها وثوزيعها، مما أدى إلى ولى تحسينات مهمة في رفاه الإنسان. وتتطلب الجهات الفاعلة التي تقوم بإدخال تغييرات نظمية نحو نظم غذائية أكثر صحة و إنصافًا وقدرة على الصمود و استدامة، إدخال تكنولوجيات على طول النظم الغذائية بحيث تكون تكنولوجيات جديدة ومبتكرة وذات إمكانات تحويلية جاهزة لاعتمادها. ثمة أيضًا حاجة إلى تحسين البيانات و التحليل و أدو ات صنع القر ار في تنفيذ حافظات السياسات و الاستثمار ات لإحداث التحولّ السريع للنظم الغذائية. ويجري حاليًا استكشاف وسائل جديدة للاستفادة الكاملة من ثورة البيانات للمساعدة في تحويل النظم الغذائية و الزر اعية في جميع أنحاء العالم، بما في ذلك النمذجة و التحليلات الجغر افية المكانية المتقدمة لتحديد فرص زيادة الدخل، وتقليل مو اطن الضعف لدى سكان الريف الذين يشكلون السو اد الأعظم من فقر اء العالم. الابنكار ات على طول سلسلة القيمة الغذائية، على عكس بعض الافتر اضات الأولية، أظهرت معظم سلاسل الإمدادات الغذائية بأنها قادرة على الصمود و استمرت في العمل، حيث ثم اعتماد الابتكارات و اتخاذ قرار ات سريعة لحماية سلاسل الإمدادات الغذائية باعتبار ها "خدمة أساسية" خلال الجائحة و على الرغم من تطبيق هذه التدابير على نطاق أوسع على سلاسل الإمدادات الحديثة و المتكاملة رأسيًا بدلًا من سلاسل الإمدادات الغذائية التقليدية، فإن التدابير المتخذة خلال جائحة كوفيد -19 قد عجلت بالتغبيرات في سلاسل الإمدادات الغذائية في جميع أنحاء العالم. و انتشرت عدة ابتكارات وتكنولوجيات جديدة بسرعة، بما في ذلك التوسّع غير المسبوق في الرقمنة، للحفاظ على سلاسل الإمدادات الغذائية خلال فتر ات الإقفال و القيود المفروضة على نظم النقل والتوزيع، ويمكن للتكنولوجيات الجديدة أن تعزز بشكل 
فعال قدرة النظم الغذائية على الصمود في وجه الدو افع الكامنة ور اء انعدام الأمن الغذائي وسوء التغذية

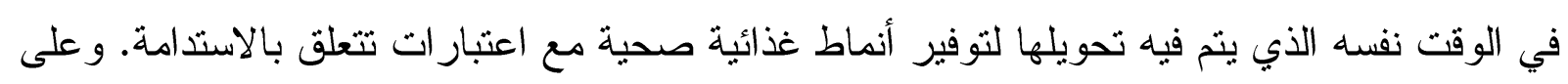
سبيل المثال، تُعتبر نظم الريّ التي تعمل بالطاقة الثمسية مر اعية للمناخ وموثوقة وميسورة الكلفة إذا تمت إدارتها بشكل مناسب، ولا يقتصر مجال الابتكار على التقدم العلمي أو الهندسي فحسب. فعلى سبيل المثال، سيتطلب الاستثمار الكبير المطلوب لتحويل النظم الغذائية آليات تمويل جديدة ومبتكرة، بالإضافة إلى تمكين الأطر القانونية و التنظيمية، بينما يمكن للمكونات المبتكرة في بر امج الحماية الاجنماعية أن تزيد من فعاليتها، وتحسّن استدامنها ونأثير اتها الإيجابية في ثيسير الوصول إلى أنماط غذائية صحية للفئات الأكثر ضعفًا.

\section{4.الاستفادة من الحلول التي تصب في مصلحة الجميع وإدارة المقايضات} إن التحوّل الناجح للنظم الغذائية من أجل زيادة القدرة على تحمّل كلفة الأنماط الغذائية الصحية للجميع و المنتجة بشكل مستدام، ومع تحسين القدرة على الصمود في وجه الدوافع المحددة، يقتضي الاستفادة الكاملة من الحلول التي تصب في مصلحة الجميع و إدارة المقايضات بعناية. حيث يسفر اعتماد التكنولوجيات والابتكارات الجديدة، والتغييرات اللاحقة في أداء النظم الغذائية، عن إحداث آثار غير مباشرة إيجابية وسلبية، ويؤدي الاتساق بين النظم المذكور، بالإضافة إلى العوامل المسرّعة الثاملة،

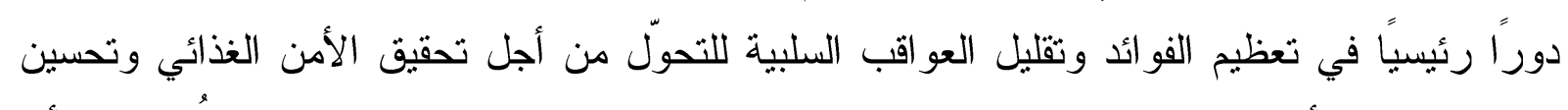
التغذية وجعل الأنماط الغذائية ميسورة الكلفة. ولذلك، هناك حاجة لاتساق السياسات، الذي يفهم على أنه حالة لا يقوض فيها تتفيذ السياسات في مجال ما المجالات الأخرى بل إنها تعزز بعضها البعض حيثما كان ذلك ممكنًا لبناء حافظات تحويلية متعددة القطاعات. 